\title{
Inequality in energy and climate policies: Assessing distributional impact consideration in UK policy appraisal
}

\section{Zimmermann ${ }^{1,2}$, Michel and Pye, Steve ${ }^{2}$}

1) Laboratory of Environmental and Urban Economics, École Polytechnique Fédérale Lausanne, BP 2133 (Bâtiment BP), Station 16, 1015 Lausanne, Switzerland, michel.zimmermann@epfl.ch,

2) UCL Energy Institute, University College London, 14 Upper Wolburn Place, London WC1H, United Kingdom, s.pye@ucl.ac.uk

\begin{abstract}
The decarbonisation of the UK economy requires a myriad of policies that inherently produce winners and loser across society. This study investigates how such distributional impacts are considered in the appraisal process for UK energy and climate policies. Using a scorecard developed to capture the guidance on policy appraisal and distributional analysis, 79 impact assessments were evaluated. The majority of these impact assessments either did not or only partially considered the impacts of policies on vulnerable groups in society, with only eight assessments containing more detailed distributional analysis. Moreover, a bias seems to exist as to which areas of energy and climate policy provide well-founded analysis and which do not. With further insights gained from interviews with relevant actors, this research concludes that political motivation, analytical difficulties and a lack of awareness of the prevalence and importance of distributional impacts are at the root of this insufficient consideration. Possible alterations to the current IA framework are presented, which aim to more firmly embed the distributional impact assessment in the appraisal process.
\end{abstract}


Key words: Distributional Impacts, Policy Appraisal, Impact Assessments, Energy Transition,

\section{Climate Policy}

\section{Highlights:}

- UK energy and climate policy appraisal contains limited distributional analysis

- Two out of three impact assessments did not consider distributional implications

- Only $10 \%$ of the analysed impact assessments were of a satisfactory quality

- Distributional impact analysis varied largely between different policy areas

- The appraisal process needs changes for better recognition of distributional impacts

\section{Introduction}

In the fight against climate change, the UK government has committed to ambitious emission reduction targets in order to contribute to international efforts to avert the dangers associated with global warming (CCC, 2016). Achieving these will require an energy transition on an unprecedented scale and while the exact figures are hard to determine, enabling a low-carbon energy system alone is estimated to incur significant additional costs (or investments) of around 1-2\% of the UK GDP (Pye et al., 2015). A successful decarbonisation strategy therefore depends on the political support and public acceptance and awareness of this system change (Watson et al., 2014). Societal expectation is for the energy transition to include considerations of energy security, affordability, personal freedom, social justice and fairness (Parkhill et al., 2013); policy-makers thus need to consider many aspects when designing and implementing policies in order to avoid opposition and garner buy-in.

However, as energy and climate policies intend to reconfigure consumption and production patterns (Kriström, 2006), they are likely to produce winners and losers within society by distributing benefits and costs unevenly (Li et al., 2016), which could diverge from people's expectations for social justice and fairness. For example, when analysing the effect in 2013 of the impact of energy and climate policies, either implemented by or planned for, on households' energy bills, significant differences between different income deciles were revealed (DECC, 2014a). The potential for disproportionate impacts on the most vulnerable groups in society require that distributional impacts (DIs) receive particular attention by policy-makers when designing policies. 
An important way to mitigate such DIs is by recognising them in the policy appraisal process. According to Deighton-Smith et al. (2016), the assessment of DIs usually focuses on one of two aspects: a more macro-oriented approach evaluating which groups in society are affected the most (e.g. consumers vs. businesses) and an "equity-perspective" (p. 20), which specifically sheds light on how the most disadvantaged groups in society are affected by a given policy. This paper focuses on the latter with the macro-oriented approach to distributional analysis deemed as insufficient, reflecting an emerging body of work highlighting the need for climate and energy policy to consider issues of fairness and justice when designing policies (Walker, 2010; Jenkins et al., 2016).

Policy appraisal is the procedure in which policies and their underlying options are evaluated ex-ante with respect to the costs, benefits and impacts that may arise as a result of the intervention. In the UK, the appraisal of policies is typically undertaken with an Impact Assessment (IA), a practice first established in the early 2000s in order to make UK policy-making more evidence-based (Cabinet Office, 1999). It was also considered crucial for sustainable development and better regulation (HM Government, 2005; Russel and Turnpenny, 2009). The Better Regulation Framework Manual (BEIS, 2015) is the primary guidance manual for government departments undertaking IAs. It defines the criteria that trigger the requirement for an IA and lays out the procedure policy-makers then have to follow using a specific toolkit. This includes the identification and description of all potentially affected groups and impacts. An important notion in this context is proportionality. It guides the choices concerning the required level of analytical detail, such as whether impacts should be quantified, monetised or whether a qualitative discussion suffices. This manual is complemented by the Green Book (HM Treasury, 2011), which has been dubbed "the bible on appraisal" (Turnpenny et al., 2014, p. 249) and illustrates the various tools that are available when assessing the effects of a proposal. This includes the cornerstone of any appraisal, cost-benefit analysis (CBA), and multi-criteria analysis (MCA), which is to be used when no quantitative assessment is possible. Completed IAs are then scrutinised by the Regulatory Policy Committee (RPC) who provide advice on whether the analysis and evidence is of sufficient quality to proceed with the proposal (RPC, 2014). 
How DIs are to be assessed as part of an IA is primarily defined in the Green Book (HM Treasury, 2011), which mandates a thorough identification and quantification of the "distribution of costs and benefits of intervention across different groups of society" (p.91) based on the following possible dimensions: gender, ethnic group, age, geographical location, disability and income. Furthermore, in order to accurately display the distributional implications of the most prevalent dimension, income, an equity-weighting CBA approach is recommended, which aims to differentiate the diminishing marginal utility of consumption among different strata by use of distributional weights. While this aims to provide a more accurate representation of the net present value (NPV), the challenge of estimating such weights is acknowledged and policy-makers are instructed to invest proportionate resources and effort. The guidance material thus appears to offer only limited assistance to policy-makers on how to assess DIs. This distributional deficit in guidance was also determined by Walker (2007), however not only for IAs, but across a large number of policy appraisal methods in the UK. It is therefore not surprising that an OECD report (Deighton-Smith et al., 2016) identified a lack of distributional analysis within IAs across a wide range of jurisdiction, including the UK. Robinson et al. (2014) confirms these findings for US policy appraisal.

Given the potential for DIs to disrupt the societal buy-in to the UK energy transition and the possibilities that policy appraisal offers in mitigating them, this paper analyses, for the first time, a set of UK energy and climate policy IAs with respect to their treatment of DIs and the quality thereof. It further provides an assessment of the adequacy of the current IA framework as a tool to enable equitable policies by shedding light on policy-makers' adherence to the available guidance and thus tests the aforementioned distributional deficit. In doing so, this provides insights into the challenges policy-makers face when undertaking IAs and allows for the identification of ways to improve the analysis of DIs for energy and climate policies.

Section 2 reviews the literature on the different aspects of policy appraisal and the role and application of distributional analysis within this process. Section 3 introduces the regulatory scorecard method, which is used to systematically analyse the sample of IAs to facilitate a comparison across these assessments and make statements about their quality. This is complemented by a selection of semi- 
structured interviews with experts to elicit additional information concerning the challenges policymakers face. The results of the scorecard application will be discussed in Section 4, followed by a synthesis of these findings in conjunction with the insights gained from the interviews. Section 5 offers concluding thoughts on the future application of distributional analysis in policy appraisal.

\section{Literature Review}

The existence of DIs and their measurement is well documented in the literature. For instance, studies in multiple countries including the UK, the US and Germany have shown that carbon taxes have regressive impacts on energy bills (Feng et al., 2010; Schlör et al., 2013; Frondel et al., 2015). However, there have also been studies partially (Rausch et al., 2011) or completely (Tiezzi, 2005) contradicting these findings. As both the type of policy (Böhringer et al., 2017) and its specific design (Rao, 2013) have been shown to influence the extent of DIs, it is crucial for policy-makers to consider distributional analysis when developing policies. Due to the potential of the policy appraisal process to assess and evaluate DIs prior to finalising and implementing policies (Walker, 2007) and its use by countless institutions and governments worldwide, it therefore merits a closer look regarding the possibilities it provides with respect to DI considerations.

Policy appraisal is designed to improve the exchange between governmental departments and therefore to align crosscutting topics across government. It is further described as a helpful tool to counter interest-biased policy development with its evidence-based methodology, to allow for increased public deliberation and to make policy-making more informed and rational (Turnpenny et al., 2009). Despite these possibilities, policy appraisal and IAs specifically have also faced some considerable criticism regarding the question whether IAs actually enable the aforementioned goal of more evidence-based policy-making (Russel and Turnpenny, 2009).

The literature on policy appraisal can be divided into four parts - models of appraisal, appraisal tools, effectiveness and motivation (Turnpenny et al., 2009). Owens et al. (2004) describe two models of appraisal. The technical-rational model, inherent to most current appraisal methods and tools in the UK (ibid.), depicts policy-making as a linear approach that seeks to determine the best policy by using 
objective empirical data. However, there are legitimate concerns in the research community that this technical-rational mode is actually able to provide sufficient evidence-based policy-making. Moreover, it tends to strongly favour economic assessments at the expense of wider impacts, such as DIs (Hertin et al., 2009). An alternative approach, the deliberative model, champions an iterative, more conceptual learning, in which "knowledge enlightens policy makers by slowly feeding new information, ideas, and perspectives into the policy system" (p. 1187) and elements of argumentation and deliberation among individual subjective stakeholders are crucial. While this iterative model is thought to potentially enable a stronger evidence base for policies, it has seen very little use by policy-makers (Adelle et al., 2012). Owens et al. (2004) recommends an integrated approach of the two models in order to improve policy appraisal and include new aspects, such as distributional analysis.

On appraisal tools, a body of research exists on existing and novel tools and methods available for policy appraisal, which aims to inform, guide and support the practices of policy-makers (De Ridder et al., 2007; Lee, 2006). For instance, the two-stage integrated appraisal (Eales et al., 2005) serves as an example of a policy appraisal method that also tries to account for impacts beyond the economic sphere, such as DIs. Furthermore, there is much literature on the myriad of tools at policy-maker's disposal to estimate these impacts, including simple tools (Nilsson et al., 2008) designed to assist policy-makers in gathering the relevant knowledge for a proposal and formal tools that employ a more thorough and analytical approach (e.g. Turner (2007) for CBA or Pohekar and Ramachandran (2004) for MCA). Complex computer-based modelling tools also constitute possible appraisal tools, such as the model developed by the Centre of Sustainable Energy in the UK designed to estimate DIs of decarbonisation policies (White, 2014). Reflecting on the (distributional) limitations of CBAs, Turner (2007) calls for a more combined use of these tools in order to meet today's requirements for equitable policies. However, with respect to their actual application, Nilsson et al. (2008) found a tendency among four European jurisdictions towards the use of simple tools, even though they also underline that the complexity of today's IAs would demand otherwise, particularly with respect to environmental, social and distributional impacts. 
The third type of literature studies concerns the effectiveness of appraisal, by investigating the relevance and adequacy of the assessed impacts, the evidence base of a proposal and thus ultimately whether appraisal practices are of the desired quality. This can be measured by comparing policy appraisal documents to the available guidance, as well as through case studies by interviewing practitioners (Adelle et al., 2012). The assessment of impact has often been described as rather insufficient (Cecot et al., 2007), especially with respect to the monetisation of social and environmental impacts, which tend to be crowded out by economic ones (Jacob et al., 2008). Nielsen et al. (2006) similarly found the extent of distributional analysis in appraisals to be inadequate, particularly with respect to quantitative assessment.

The final strand concerns the question of whether appraisal processes have a wider motive beyond making better policy. One suggestion is that IAs are designed to increase political power over the bureaucracy (Radaelli, 2010b), which indeed appears to be the case for the UK (Radaelli, 2010b). It thus could be viewed as a tool to reaffirm already taken policy decisions, as indicated by Hertin et al. (2009). Finally, Radaelli (2010a) offers the notion that policy appraisal may simply constitute a regulatory necessity or be of only symbolic value for policy-makers. An understanding of the underlying motivation for policy appraisal is important for DI considerations, since it could provide alternative explanations for their exclusion or inclusion by policy-makers.

The literature points to different approaches to policy appraisal, and the practical inclusion of DIs into the process. Distributional analysis itself however has been described as a developing field across all types of policies (Deighton-Smith et al., 2016) and its role and use in policy appraisal has received only limited attention in the research community. Robinson et al. (2014) explain this neglect as a result of a view amongst policy-makers that minimalistic distributional analysis suffices and that it may not be proportionate to assess DIs more comprehensively. They also offer the notion that it may not be practical nor proportionate to routinely include an elaborate distributional analysis in IAs, as the costs to gather the necessary evidence could regularly outweigh the benefits of stronger scrutiny, as noted by Nielsen et al. (2006). For energy and climate policies in particular, we are not aware of anything comparable and this study thus intends to fill this gap. 


\section{Methodology}

Morgenstern and Harrington (2004) illustrate three possible tests to assess the performance of IAs: content, outcome and function tests. While all of them provide valuable information and are considered complementary, only the content tests suit this study's purpose by evaluating ex-ante policy appraisal and investigating its role in providing just and equal policies. In order to assess the extent and quality of distributional analysis in IAs of UK energy and climate policies, this research employs a regulatory scorecard method, following the approach by Hahn et al. (2000).

To employ this method, a scorecard is first designed, which consists of a set of key criteria that reflect the content and philosophy of the regulatory guidance material. The IAs are then checked against these criteria and scored according to a point-based scoring system. This contributes to the research threefold. In addition to collecting evidence on the use of distributional analysis in UK IA, it determines the level of compliance with the guidance (Cecot et al., 2007) and allows for the comparison of different criteria across IAs. Furthermore, it provides an indication of the overall quality of a given IA in relation to the sample in question, when all of them are based on the same guidance material (Hahn and Dudley, 2007). This method has been used to evaluate the quality of regulatory IAs in the US (Hahn et al., 2000), in the EU (Renda, 2006; Cecot et al., 2007) and the UK (NAO, 2009).

Hahn and Dudley (2007) describe the main advantage of this method as capturing whether different elements of the guidance have been included, but without a requirement to assess the quality of the underlying assumptions and calculations. The limitation of the approach is that while guidance may have been followed, with all elements of the appraisal included, the methodology applied may in fact be flawed. Furthermore, this approach does not enable an assessment of the impact on the analytical process on the regulation or policy being considered. Given the focus of this paper on the identifying key elements of DIs addressed, the approach is well suited.

A second part of the approach, as per that of Nilsson et al. (2008) and the NAO (2011), was to interview a number of key stakeholders to complement the scorecard findings. This was to better contextualise and interpret the scorecard results. The interviewees selected comprise of two policy-makers involved 
in IAs for UK energy and climate policies, a professional involved in the creation of the Green Book, the main guide for distributional analysis, and an academic expert providing additional objective insights. As the focus of engaging a diverse set of interviewees was to understand different perspectives, the respective interview guides were customized according to the expertise and profession of the participants. The questions revolved around the IA procedure and the role of DI therein for the policymakers, the distributional elements in the guidance for the policy appraisal expert, and the current statusquo in policy appraisal and distributional analysis for the academic representative.

\subsection{Data}

The Government database, legislation.gov.uk, contains most UK legislation and corresponding supplementary documents, including IAs (The National Archives, 2017) and thus was the primary data source. As the Climate Change Act 2008 officially laid out the government's commitment to reduce emissions, only IAs published after its implementation were considered. The analysis further was limited to assessments undertaken by the governmental body immediately responsible for the implementation of said act and the energy transition, namely the Department for Energy \& Climate Change (DECC). ${ }^{1}$ While other departments, such as transport (DfT), also develop policy proposals in this area, the vast majority for the timeframe considered were from DECC. Moreover, the sample of interest comprises only those IAs in the final stage of the policy development process. Using these initial parameters, the database yielded 249 hits. However, many IAs were nearly identical with only minor updates or amendments. As a consequence, the extracted sample was reduced to 133 IAs undertaken by DECC between 2009 and 2017. Furthermore, only climate and energy policies immediately relevant to decarbonisation were considered. As a result, additional screening saw many IAs from a range of policy areas on oil, electricity, nuclear energy and gas (apart from carbon capture and storage (CCS)), offshore activities and grid infrastructure removed from the sample. For the sake of clarity, the remaining 79 IAs were bundled into four thematic categories: Power generation,

\footnotetext{
${ }^{1}$ The functions of DECC have since been transferred to the Department for Business, Energy and Industrial Strategy (BEIS).
} 
Buildings, Climate Change (cross-sectoral) and CCS. Appendix 2 gives an account of all IAs that have been analysed and their categorisation.

\subsection{Research Design}

To enable an accurate assessment of policy-makers' compliance with the guidance, the key guidance criteria must be appropriately represented in the scorecard framework. The framework used therefore draws upon a similar analysis by the NAO (2009) of 480 IAs and adapts its methodology (pp. 22-23) in order to accommodate for this study's specific focus on DIs. Following an in-depth analysis of the manuals regarding their treatment of DIs and their guidance on IAs in general (BEIS, 2015; HM Treasury, 2011), scoring questions and corresponding answer options were established covering the three main categories.

Firstly, the guidance instructs practitioners to provide as much qualitative and quantitative evidence on the different options of proposed legislation as is deemed proportionate, including the costs and benefits of each option presented. After general questions about the nature of the IA, the scorecard therefore captures the number of presented options and the extent of the cost-benefit assessment.

Secondly, the IA toolkit requires that a broad range of economic, social and environmental impacts are considered and, if applicable, analysed. The Green Book further characterises how distributional analysis should be approached and emphasises the importance of acknowledging all distributional dimensions that could be affected. The next questions thus ask whether economic and environmental impacts have been discussed, as well as social impacts that potentially bear significant distributional implications. In addition, one criterion aims to capture if DIs have been considered at all. Following the equity perspective adopted in this study, distributional analysis ideally needs to explicitly illustrate the unequal distribution of costs and benefits among different income groups. Furthermore, the scorecard also acknowledges that assessments that focus on the fuel poor (i.e. how a policy impacts the amount of people who spend disproportionately much on heating) are assessing distributional implications, even if the concept of DIs is not mentioned. Finally in this category, a question seeks to determine whether the IAs without any assessment of DIs have justified this omission, as is required by the guidance. 
Thirdly, three questions focus on the extent of the assessment undertaken based on the tools that the Green Book recommends, particularly for distributional analysis. They capture whether DIs have been discussed qualitatively, whether DIs have been quantified by measuring the change in number of fuel poor amongst society and whether DIs have been monetised and included in the final NPV calculation. The scorecard answer options also differentiate as to whether the distributional analysis was undertaken for all presented options, for only the lead option of the proposal or only in a generic manner in the case of a qualitative assessment. Furthermore, two criteria are included to capture if distributional weights for a more accurate representation of the NPV, which was introduced above as equity-weighting, have been used, as well as if MCA was applied for cases that have been deemed unfeasible to quantify. In addition, a question is included to identify whether the extent of distributional analysis or the absence thereof has been justified and thus investigates the introduced notion of proportionality. Finally, the last two questions of the scorecard register whether any potential measures were discussed to mitigate negative DIs that had been identified and whether DIs had any discernible influence on the design of the IA.

To allow for a comparison of the IAs, a scoring system for the scorecard answers was developed. The majority of questions are simple yes-no questions, which translates to 1 or 0 . However, some questions require more nuanced responses and therefore cover a wider range of points. A not applicable (N/A) option is also included for every criterion. The N/A option for the question on whether the absence of DI consideration was justified is rewarded equally to the 'Yes'-answer for cases where distributional analysis was actually undertaken. To improve comparability, the IAs are then ranked according to a traffic light system, with 'green' signifying good and well-founded, 'amber' medium and limited in scope, and 'red' poor and inadequate quality. The full scorecard with all key criteria and scoring system is shown in Appendix 1.

To assure the scorecard's quality and suitability, two quality checks were performed after the first 30 IAs had been analysed and scored. As part of an analyst testing (HM Treasury, 2015), we reflected upon the evidence and scores of the first tested sample by testing them for irregularities, ambiguities and overall robustness. Moreover, 5 randomly selected IAs were checked and scored by a peer of the 
researchers and any observed discrepancies were discussed. One finding concerned a lack of answer options for the question on qualitative DI assessment. Another issue that emerged was a skewness of the 'traffic light' scoring system towards question which were not immediately pertinent to distributional analysis, leading to the omission of the first six questions in the overall score. As a result, IAs with 14-20 points were flagged green, 7-13 amber and 0-6 red. 16 of these 20 points stem from question categories 2 and 3 and directly relate to DIs.

The final scorecard was then systematically applied to the entire sample. After using the first-page summary of each document to get familiar with the IA in question, the IA was scanned for information pertinent to the criteria and the results and scores were gathered in an excel file. Notes about the key issues of every IA were further taken to allow for reconciliation of all answers after the application was finished. This is particularly important since many decisions were based on the subjective opinion of the researchers and thus left some room for interpretation.

\section{Results}

The application of the regulatory scorecard shows that DIs are not only inadequately considered in energy and climate IAs, but also tend not to meet the expectations and requirements outlined by the guidance. As is shown by Figure 1, only 28 or $35 \%$ of the sample actually contained some type of distributional analysis and thus have, at a minimum, either explicitly or implicitly acknowledged potential distributional implications of a proposal. Meanwhile, a total of 51 IAs failed to discuss any distributional implications and were thus all flagged red. However, among the 28 IAs, the quality varied significantly; while approximately $60 \%$ of these IAs were of medium quality, there were still three IAs that received a red rating. Appendix 2 shows the scores and ratings of all analysed IAs.

Figure 1: The Amount, Quality and Extent of DI consideration 

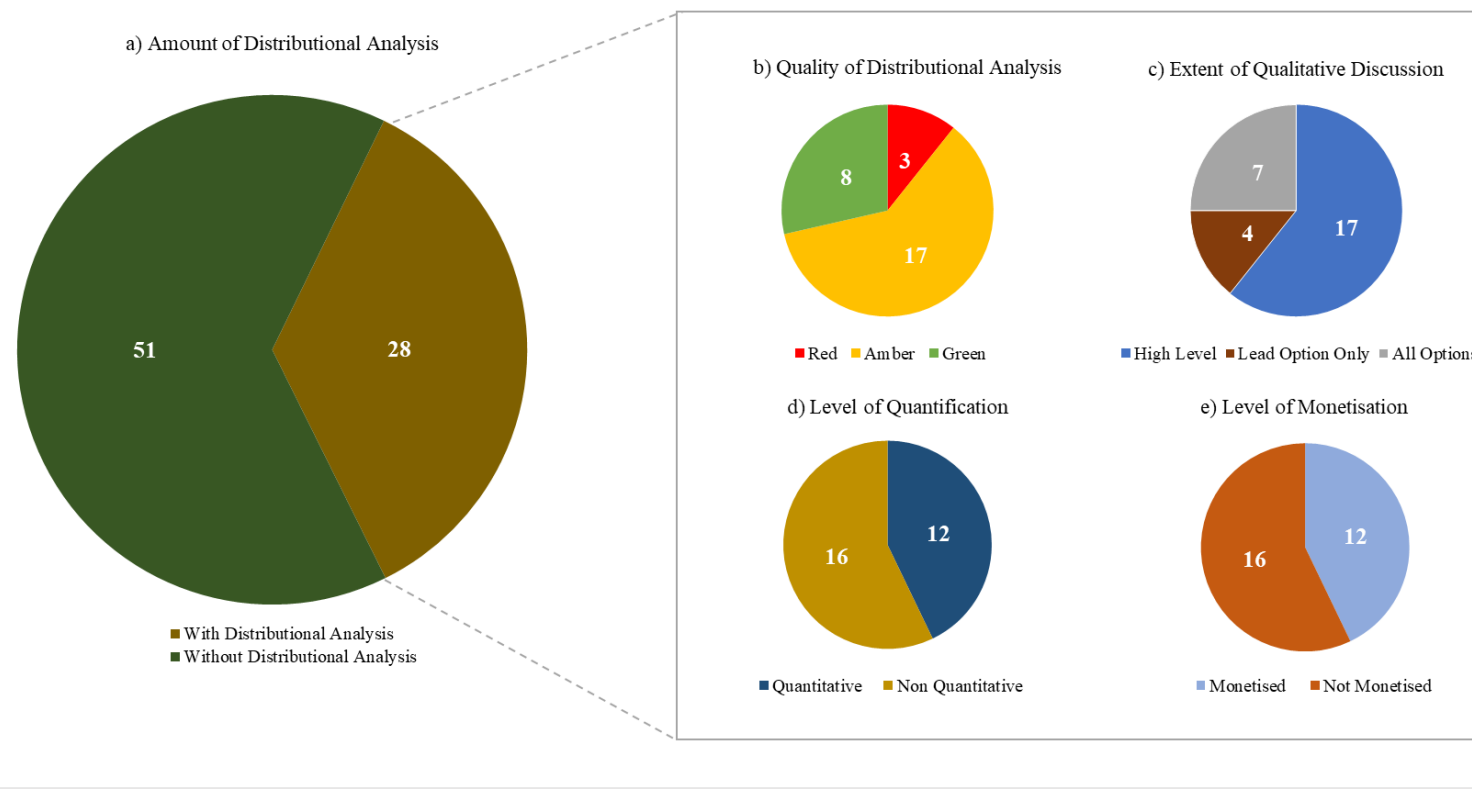

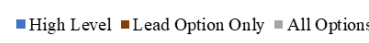

e) Level of Monetisation

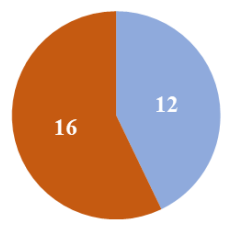

Monetised Not Monetised

Source: Authors

Figure 1 further illustrates how this subset of 28 IAs, which included some form of DI discussion, differed in the extent of distributional analysis. Most of the qualitative distributional analyses were limited to high-level discussion of the hypothetical distributional implications without actually referring to the specific options of a given proposal. More detailed assessments in this sample were rarely conducted, as exemplified by the fact that only 4 of the 28 IAs actually discussed the DIs that were to be expected when implementing the lead option of the policy. This appears to show a reluctance by policy-makers to go 'the extra mile' when appraising DIs. Conversely, for the higher scoring IAs, they seem to have both a well-founded qualitative assessment of DIs and quantification or monetisation of the described impacts. Across the 28 IAs, both the impact on the number of fuel poor and on the energy bills of vulnerable groups were only estimated for 12 IAs.

As indicated in Figure 1, eight IAs received a green rating and were thus considered to have discussed DIs in a well-founded manner, which constitutes only $10 \%$ of the entire sample (of 79). While all eight of them have assessed DIs both explicitly and implicitly in varying degrees of detail, one particular commonality is their use of distributional weight to reflect DIs in NPV calculations. An interesting case is the IA "The Future of the Energy Company Obligation" (DECC, 2014b). It indicated that the positive distributional effects of the proposal could increase the policy's NPV by up to $£ 2.4 \mathrm{bn}$ if equity weights 
were applied. Nevertheless, it did not include this in the final NPV value but failed to justify why. The inability to explain policy-maker's rationale was a frequently encountered issue, with limited justification. Only half of the 28 IAs provided some explanations concerning the comprehensiveness of their DI discussion, including all three IA rated as red.

Finally, the scorecard assessment also found significant differences between the extent to which certain policy areas performed distributional analysis. Policies designed to support renewable energy mostly neglected the assessment of DIs, with only one in five policy appraisals including a discussion of the distributional implications. Meanwhile, policies setting the regulatory framework to tackle climate change, such as the appraisal of the fifth carbon budget (DECC, 2016) and those designed to increase the sustainability and energy efficiency of buildings attributed more importance to distributional analysis. This latter group in particular discussed DIs in three out of five cases. While it intuitively makes sense that such IAs tackle DIs given their direct effect on fuel poverty, the reasons for the low uptake of DI analysis for other policies, such as renewable energy, is less clear.

51 IAs did not undertake distributional analysis in line with the equity-perspective applied in this study. As Figure 2 shows, this included 12 IAs that used a different, more aggregate definition of DIs, whereby the impact on bills for consumers and businesses or domestic and non-domestic consumers were considered, but not on vulnerable groups. These IAs were deemed inadequate and thus flagged red as they fail to demonstrate the impact of changing bills across different income groups. All but one of the 12 IAs concern power generation policies, which to some extent explains this sectoral policy area's poor performance.

Figure 2: 51 IAs without distributional analysis 


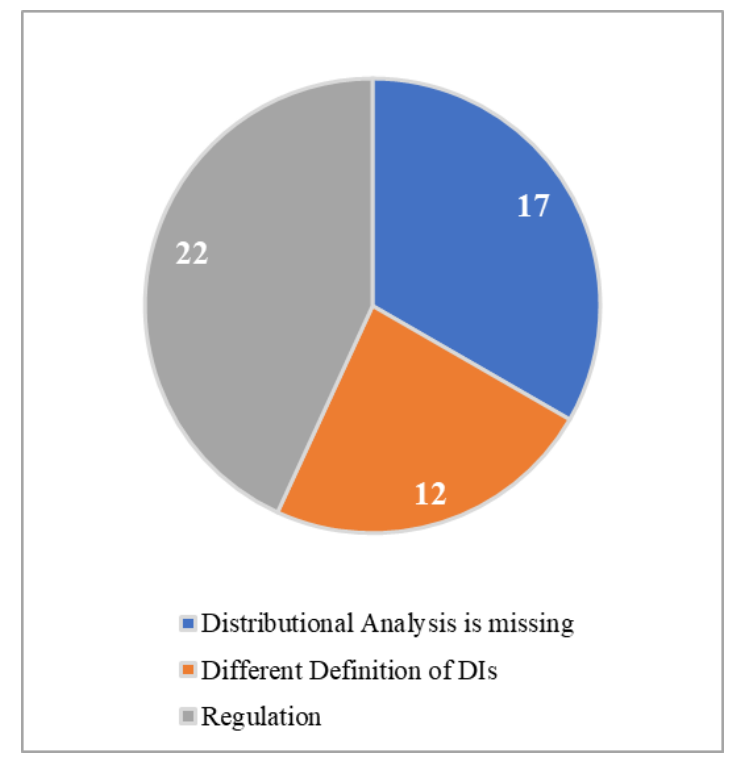

Source: Authors

The remainder of IAs which omitted any discussion of the distributional implications can be categorised into two groups. The first and larger group comprises of 22 IAs that concern amendments of existing regulations or the simple implementation of new regulations, as well as transpositions of EU law into UK law. Overall, these policies rarely impose significant immediate costs or benefits. Consequently, the decision to forgo distributional analysis is understandable, even though the case for including a short explanation as to why DIs were not assessed could be made nonetheless. In the second group, as Figure 2 indicates, there were 17 IAs, approximately $20 \%$ of the total sample whose focus and projected policy outcome suggests distributional implications that should have triggered distributional analysis. However, they failed to address any possible DIs, even in a qualitative manner. Many relate to the support for renewable energy generation, policies that could certainly have implications for energy prices and bills. The omission of distributional analysis thus does not seem justified without further explanation.

Böhringer et al. (2017) showed that the size of DIs depends on the specific design of a given policy option. If minimising DIs was therefore the intention, the normative statement could be made that multiple options of the policy in questions need to be assessed to determine the policy option leading to the least distributional implications. Interestingly, the findings here suggest that the IAs considering 
multiple options tended to be those that produced a more thorough discussion of DIs. IAs that appraised DIs presented multiple options almost three out of four times, whereas more than $60 \%$ of DI without distributional analysis rarely included more than a lead option and its counterfactual.

In general, an apparent trend was observed between the overall quality of an IA and the extent to which distributional analysis was conducted. For example, IAs without DI discussion only assessed social impacts with a distributional dimension (e.g. effects on rural populations or on gender) in little more than half of all the cases (55\%) compared to the $75 \%$ for IAs with distributional analysis. Similarly, economic and environmental impacts have been considered more frequently for the 28 IAs, which considered DIs in line with the equity perspective. It can therefore be inferred that close compliance with the manuals and thus assessing a wide range of impacts appears to lead to better distributional analysis.

\section{Discussion}

These findings indicated that the distributional deficit in UK policy appraisal identified by Walker (2007) exists across IAs for energy and climate policies, with only a third containing at least some distributional analysis. Based on insights from the literature and the interviews conducted, possible explanations for this outcome are now presented.

One apparent issue is the lack of clarity in understanding of what policy-makers are to consider when discussing DIs, which resulted in some IAs only assessing the distributional effects for certain macrogroups in general rather than focusing on the particularly vulnerable groups within society. This is due to the fact, as mentioned by the Green Book expert, that the Green Book definition of a DI is very broad as it has to serve as the basis for policy appraisal across a myriad of different governmental agencies. Deighton-Smith et al. (2016) discovered similar patterns and argues that in order to maximise compliance with the guidance and distributional analysis in general, a clear definition is paramount.

While this may illustrate the approach for some IAs, it fails to explain why DIs have either been rudimentary in nature or lacking entirely for a large proportion of the sample. Given the possible 
implications of policy proposals on the disposable income of individuals, the analysis of DIs has an underlying political dimension. Hence, as Robinson et al. (2014) states, it could be inferred that policymakers may willingly choose not to assess DIs in great detail, if at all, in order to avoid revealing negative implications, which could delay or prevent legislation from being implemented. One interviewed policy-maker agreed with this notion, stating the political nature of DIs to be one of its main complexities. The designated wider purpose of policy appraisal is another issue to consider, particularly since Radaelli (2010a) found UK policy appraisal to enable a high level of political control for decision-makers over bureaucracies. If IA are intentionally misused to reaffirm decisions that have already been taken rather than finding the best policy options, this therefore would substantially diminish the potential for policy appraisal to help bring about more equitable policy-making.

While the Green Book expert stressed that the guidance with its definition of DIs is designed to keep policy and thereby politics at arm's length, the presented findings do suggest certain political motivation behind the use of distributional analysis. All policy proposals that ended up with a green rating and thus undertook careful and elaborate distributional analysis projected bill savings for consumers and even applied distributional weights to further emphasise the distributional benefits and the legitimacy of the proposal. Conversely, legislation incentivizing renewable energy generation, which has in the past been considered an inflator of energy bills (Croft et al., 2012, pp. 68-69) and thus politically contentious, contained little to no distributional analysis. The rationale behind distributional analysis therefore seems to follow a 'pick-and-choose' logic, depending on the policy area and the expected outcome. One policy-maker disputed wilful negligence, however, occasional politically motivated actions were acknowledged.

While politically motivated behaviour is difficult to rule in or out, another explanation stems from the failure to overcome analytical difficulties policy-makers encounter when dealing with distributional analysis. An interviewee with policy appraisal expertise stated that "collecting evidence and come up with a counterfactual proposal $[\ldots]$ is analytically challenging" and that the available guidance in the Green Book tends to be too general. This issue is not limited to the UK, as Robinson et al. (2014) observed a similar lack of guidance for the analytical discussion of DIs from US regulations. 
Concerning the generality of the guidance, the interviewee emphasised that this is precisely its intended purpose. The analytical difficulties however were acknowledged, especially with respect to defining distributional weights. Although, when asked whether policy-makers had many problems or questions about distributional analysis, this was denied. Difficulties with the assessment of DI are thus most likely contribute to the lack of quantification or monetisation, albeit only to a certain extent.

In fact, policy-makers appear to have limited awareness about the significance and possibilities of distributional analysis in general. Two findings support such a notion. The first one relates to the guidance on justifying the chosen treatment of DIs in every IA and the policy-makers' frequently observed failure to follow. While one could dispute the proportionality of including such a justification for cases where no DIs are to be expected, other specific impacts (e.g. impacts on competition, wider environment and on rural areas) tended to be routinely captured in many IAs as part of a 'specific impact test' checklist, regardless of their expected size or relevance. This points to an issue of awareness rather than proportionality. One policy-maker agreed insofar as suggesting that the necessity for distributional analysis in the guidance should be more prominent.

The second reason concerns how policy-makers generally view policy appraisal. The interviewed stakeholders implied that the task of undertaking IAs was a requirement of policy-makers when developing new legislation, and sometimes viewed as an element that had to be 'checked off' rather than an integral process for improving regulatory proposals. Radaelli (2010b) further claims that the function of policy appraisal sometimes is only considered to be of symbolic nature. This is underlined by the academic interviewee, who raised doubts whether policy-makers considered IAs anything more than simply an unwelcome necessity. Thus, if the process within which DI analysis is ought to be completed is viewed as a burden, it does not create a conducive environment in which expertise and understanding of the importance of DIs can be accumulated.

As illustrated, one additional particularly interesting finding was the apparent trend observed between the IAs overall quality and the quality of the distributional analysis. This suggests that improving policy appraisal could also benefit distributional analysis. However, even with the insights from the interviews, it is difficult to conclusively discern the motives and rationales behind the choice of the extent of 
distributional analysis. Nonetheless, this section has shown that the insufficient consideration of DIs may be explained by a combination of possible reasons.

\section{Conclusion and Policy Recommendations}

This study has investigated UK energy and climate IAs with respect to how DIs are considered and has aimed to establish whether the distributional deficit postulated by Walker (2007) also exists in this crucial field of policy-making. Moreover, it considered the level of adoption of the available guidance on distributional analysis by policy-makers. A scorecard was developed to capture the expectations of the guidance, providing a framework to systematically review the content and quality of IAs and further allow for a comparison across different IAs. This method has illustrated both the inadequate level of distributional analysis of energy and climate policies, as well as the differences in DI consideration among the four defined areas of policies

It showed that the majority of the 79 analysed IAs had none or only rudimentary distributional analysis while few IAs analysed DIs to the extent suggested in the UK guidance, the Green Book and the Better Regulation Framework Manual. In combination with the interviews, the analysis highlighted some general issues with policy appraisal and the way DIs are covered in the manuals. It demonstrated the ambiguity of how DIs are defined in the guidance and the lack of awareness by policy-makers as to the benefits of routinely including a comprehensive account of DIs in the policy appraisal process. Finally, the diverging approach to distributional analysis between different policy areas, particularly between legislation encouraging the dissemination of renewable energy generation and policies tackling inefficient buildings, indicates that the politically contentious nature of a type of policy may influence the amount of distributional analysis undertaken by policy-makers.

This leads to the conclusion that the current policy appraisal process does not undertake thorough distributional analysis and therefore may be insufficiently capable of assisting policy-makers in developing equitable policies. To reduce this distributional deficit and help establishing better and more routine distributional analysis, two possible ways of moving policy appraisal forward are now illustrated. 
In the first option, we propose amendments to the existing policy appraisal in order to address the issues encountered in this study. First, the definition of a DI in the guidance needs to be more precise to reduce the room for interpretation by policy-makers. Furthermore, there is little evidence that UK ministries dealing with energy and climate change policy put much emphasis on distributional analysis or policy appraisal in general. As opposed to other governmental bodies in the UK (e.g. Department of Transport or Ofgem), one fails to find any form of (publicly available) support that caters to the specific issues that energy and climate policies deal with. Drafting such a departmental guidance would help with the described analytical difficulties, as well as increase the awareness among policy-makers of the importance of DIs and the possibilities of policy appraisal in dealing with them, which was underlined by one interviewee. In addition, two interviewees pointed to the potential for a more inclusive discussion of DIs if they were made a governmental priority, especially given how time-intensive distributional analysis can be and how constrained resources generally are (Deighton-Smith et al., 2016).

Given the systemic issues with policy appraisal, the second option concerns the question whether the current IA framework is even suitable for assessing DIs of energy and climate legislation. This question has also been raised in the literature (Turnpenny et al., 2008) with Walker (2007) suggesting the development of a specific DI appraisal tool. However, this would not be without challenges, as one interviewee pointed out, the effectiveness of such an alternative method is difficult to foresee. Given the current predominance of the Green Book in UK policy appraisal, it would further stand the risk of lacking the necessary acceptance by policy-makers and becoming a paper tiger.

We also propose the integration of deliberative methods in the current techno-rational policy appraisal process. This would have the effect of making IAs less linear and more iterative in nature, by putting argumentation and deliberation among stakeholders, including but not restricted to policy-makers, at the centre of its decision-making process. By putting the focus on the scope of the assessment, its process and how it is framed, policy-makers could potentially improve the evidence-base of policies. Moreover, it could reduce the barriers for the adaptation of more inclusive and transparent policymaking and also curtail the political control exercised over policy-makers. By also enabling better qualitative discussions of DIs by use of more novel methods such as the multi-criteria analysis for cases 
where quantification and monetisation is prohibitively costly, this would significantly contribute to better distributional analysis. The challenge will be to change appraisal systems and methods that are entrenched in current practice. Both a specific DI appraisal tool and the integration of deliberation in the current policy appraisal framework will require changes at a micro-level through improved training of policy-makers by relevant experts and at a macro-level by providing the aforementioned political support and an environment which fosters iterative evidence-based policy appraisal and DI analysis.

Further research is needed to better understand how DIs can be effectively undertaken to inform future UK energy and climate policy appraisal. Researchers will have to work closely with policy-makers in order to ensure alternatives to the existing policy appraisal paradigm and that potential new tools are suitable for the "messy world of policy making" (Turnpenny et al., 2008, p. 772). A key issue concerns whether the move towards DIs being systematically undertaken which are more comprehensive and robust leads to this new information informing evidence-based policy making. The exchange with policy-makers and other key actors in the field by the means of extensive interviews is thus paramount. This could also rectify a limitation of this study, which was the small number of conduced interview and the limited possible inference about policy-makers' motives and intentions. Finally, future research should further address how other governmental bodies, whose policies also significantly contribute to a successful energy transition (e.g. DfT or Ofgem), approach DIs in their policy appraisal processes and compare this with the findings presented here. This would provide further insights in the issues that arise when analysing Dis in the context of energy and climate policies. 


\section{Bibliography}

Adelle, C., Jordan A. and Turnpenny, J., 2012. Proceeding in parallel or drifting apart? A systematic review of policy appraisal research and practices. Environment and Planning C:Politics and Space. [e-journal] 30(3), pp. 401-415. http://dx.doi.org/10.1068/c11104

BEIS, 2015. Better Regulation Framework Manual: practical guidance for UK government officials. [online] London: Department for Business, Energy and Industrial Strategy (BEIS). Available at: https://www.gov.uk/government/uploads/system/uploads/attachment_data/file/583871/bis-13-1038Better-regulation-framework-manual.pdf [Accessed 05 March 2018]

Böhringer, C., Kosch, M., Landis, F., Müller, A., van Nieuwkoop, R. and Rausch S., 2017. Promotion-or Steering-based Energy Policy: Assessing Efficiency and Distributional Impacts. [online]. Available from: https://www.ethz.ch/content/dam/ethz/special-interest/mtec/cereth/economics-energy-economicsdam/documents/people/srausch/NFP71_ProSTEP_Report_LONG.pdf [Accessed 05 March 2018].

Cabinet Office, 1999. Modernising government. London: The Stationery Office (TSO).

CCC 2016. Meeting Carbon Budgets - 2016 Progress Report to Parliament. [pdf] London: Committee on Climate Change (CCC). Available at: https://www.theccc.org.uk/wpcontent/uploads/2016/06/2016-CCC-Progress-Report.pdf [Accessed 05 March 2018].

Cecot, C., Hahn, R.W. and Renda, A. 2007. A statistical analysis of the quality of impact assessment in the European Union. AEI-Brookings Working paper 07-09. [online] Available from: https://www.researchgate.net/profile/Andrea_Renda/publication/267719186_A_Statistical_Analysis_ of_the_Quality_of_Impact_Assessment_in_the_European_Union/links/555701ba08aeaaff3bf60e50.p df [Accessed 04 March 2018].

Climate Change Act 2008. (c27). London: HMSO.

Croft, D., Preston, I., Guertler, P. and Carrington, J., 2012. Impact of energy policy on consumer bills. [online]. London: Association for the Conservation of Energy. Available from: 
http://www.cse.org.uk/app/webroot/downloads/file/impact_of_energy_policy_on_consumer_bills.pdf [Accessed 05 March 2018

De Ridder, W., Turnpenny, J., Nilsson, M. and Von Raggamby, A., 2007. A framework for tool selection and use in integrated assessment for sustainable development. Journal of Environmental Assessment Policy and Management. [e-journal] 09 (04), pp. 423-441. https://doi.org/10.1142/S1464333207002883

DECC, 2014a. Estimated impacts of energy and climate change policies on energy prices and bills. [online] London: Department of Energy and Climate Change (DECC). Available at: https://www.gov.uk/government/uploads/system/uploads/attachment_data/file/384404/Prices__Bills_r eport_2014.pdf [Accessed on 03 March 2018]

DECC, 2014b. The Future of the Energy Company Obligation: Final Impact Assessment. [online] London: Department of Energy and Climate Change (DECC). Available at: http://www.legislation.gov.uk/ukia/2014/363/pdfs/ukia_20140363_en.pdf [Accessed 05 March 2018] DECC, 2016. Impact Assessment for the level of the fifth carbon budget. [online] London: Department of Energy and Climate Change (DECC). Available at: http://www.legislation.gov.uk/ukia/2016/177/pdfs/ukia_20160177_en.pdf [Accessed 06 March 2018] Deighton-Smith, R., Erbacci, A. and Kauffmann, C. 2016. Promoting inclusive growth through better regulation: The role of regulatory impact assessment. OECD Regulatory Working Papers, No. 3. [online]. Paris: OECD publishing. Available from: http://www.oecdilibrary.org/docserver/download/5jm3tqwqp1vjen.pdf?expires $=1503930365 \& \mathrm{id}=\mathrm{id} \&$ accname $=$ guest $\&$ checksum=886B913E9DFF0D79517A2DE474 F8E83C [Accessed 05 March 2018]

Eales, R., Smith, S., Twigger-Ross, C., Sheate, W., Özdemiroglu, E., Fry, C., Tomlinson, P. and Foan, C., 2005. Emerging approaches to integrated appraisal in the UK. Impact Assessment and Project Appraisal. [e-journal] 23 (2), pp. 113-123. http://dx.doi.org/10.3152/147154605781765643 
Feng, K., Hubacek, K., Guan, D., Contestabile, M., Minx, J. and Barrett, J., 2010. Distributional Effects on Climate Change Taxation: The Case of the UK. Environmental Science \& Technology, [ejournal] 44(10), pp. 3670-3676. http://dx.doi.org/10.1021/es902974g

Frondel, M., Sommer, S. and Vance, C. 2015. The burden of Germany's energy transition: An empirical analysis of distributional effects. Economic Analysis and Policy. [e-journal] 45, pp.89-99. http://dx.doi.org/10.1016/j.eap.2015.01.004

Hahn, R. W., Burnett, J.K., Chan, Y-H.I., Mader, E.A. and Moyle, P.R., 2000. Assessing the Quality of Regulatory Impact Analyses. The Harvard Journal of Law and Public Policy. [e-journal] 23(23). http://dx.doi.org/10.2139/ssrn.213854

Hahn, R. W. and Dudley, P. M., 2007. How Well Does the US Government Do Benefit-Cost Analysis? Review of Environmental Economics and Policy. [e-journal] 1 (2), pp. 192-211. https://doi.org/10.1093/reep/rem012

Hertin, J., Turnpenny, J., Jordan, A., Nilsson, M., Russel, D. and Nykvist, B., 2009. Rationalising the policy mess? The role of ex ante policy assessment in four countries. Environment and Planning A. [e-journal] 41(5), pp. 1185-1200. https://doi.org/10.1068/a40266

HM Government, 2005. Securing the future: delivering UK sustainable development strategy. [online] London: The Stationery Office. Available at: https://www.gov.uk/government/uploads/system/uploads/attachment_data/file/69412/pb10589securing-the-future-050307.pdf [Accessed 01 March 2018].

HM Treasury, 2011. The Green Book: Appraisal and evaluation in central government. [online] London: The Stationary Office. Available at: https://www.gov.uk/government/uploads/system/uploads/attachment_data/file/220541/green_book_co mplete.pdf [Accessed 01 March 2018].

HM Treasury, 2015. The Aqua Book: guidance on producing quality analysis for government. [online] London: The Stationary Office. Available at: 
https://www.gov.uk/government/uploads/system/uploads/attachment_data/file/416478/aqua_book_fin al_web.pdf [Accessed 02 March 2018].

Jacob, K., Hertin J., Hjerp, P., Radaelli, C., Meuwese, A., Wolf, O., Pacchi, C. and Rennings, J., 2008. Improving the practice of impact assessment. Evaluating Integrated Impact Assessments. [online] Available at: http://userpage.fu-berlin.de/ffu/evia/EVIA_Policy_Paper.pdf [Accessed 03 March 2018].

Jenkins, K., McCauley, D., Heffron, R., Stephan, H. and Rehner, R., 2016. Energy justice: A conceptual review. Energy Research \& Social Science. [e-journal] 11, pp. 174-182. https://doi.org/10.1016/j.erss.2015.10.004

Kirström, B., 2006. Framework for assessing the distribution of financial effects of environmental policy. In: Serret, Y. and Johnstone, N., 2006. The Distributional Effects of Environmental Policy, Cheltenham: Edward Elgar Publishing., pp. 79-139.

Lee, N. (2006) Bridging the gap between theory and practice in integrated assessment. Environmental Impact Assessment Review. [e-journal] 26 (1), pp. 57-78. http://dx.doi.org/10.1016/j.eiar.2005.01.001

Li., F. G.N., Pye., S. and Strachan, N., 2016. Regional winners and losers in future UK energy system transitions, Energy Strategy Reviews, [e-journal] 13-14, pp. 11-31.

http://dx.doi.org/10.1016/j.esr.2016.08.002

Morgenstern, R. \& Harrington, W. (2004) Evaluating Regulatory Impact Analyses. Discussion papers dp-0-04-04 Resources For The Future. [online] Available at: https://ideas.repec.org/p/rff/dpaper/dp04-04.html [Accessed 03 March 2018]

NAO, 2009. Delivering High Quality Impact Assessments [online] London: National Audit Office (NAO). Available at: https://www.nao.org.uk/wp-content/uploads/2009/01/0809128.pdf [Accessed 02 March 2018]. 
NAO, 2011. Assessing the impact of proposed new policies [online] London: National Audit Office (NAO). Available at: https://www.nao.org.uk/wp-content/uploads/2010/07/1011185.pdf [Accessed 03 March 2018]

Nielsen, U., Lerche, D.B., Kjellingbro, P.M. and Jeppsen, L.M., 2006. Getting proportions right: how far should EU impact assessment go. [online] Copenhagen: Institut for Miljovurdering. Available at: https://www.dors.dk/files/media/graphics/Synkron-

Library/Publikationer/IMV/2006/getting_proportions_right.pdf [Accessed 02 March 2018].

Nilsson, M., Jordan, A. and Turnpenny, J., 2008. The use and non-use of policy appraisal tools in public policy making: an analysis of three European countries and the European Union. Policy Sciences. [e-journal] 41 (4), pp. 335-355. https://doi.org/10.1007/s11077-008-9071-1

Owens, S., Rayner, T. and Bina, O., 2004. New Agendas for Appraisal: Reflections on Theory, Practice, and Research. Environment and Planning A. [e-journal] 36(11), pp. 1943-1959. http://dx.doi.org/10.1068/a36281

Parkhill, K.A., Demski, C., Butler, C., Spence, A. and Pidgeon, N., 2013. Transforming the UK Energy System: Public Values, Attitudes and Acceptability - Synthesis Report [pdf] London: UK Energy Research Centre. Available at: http://www.ukerc.ac.uk/asset/835A77F5-62DA-4062925917DF4D288372/ [Accessed 01 March 2018].

Pohekar, S. D. \& Ramachandran, M. (2004) Application of multi-criteria decision making to sustainable energy planning-A review. Renewable and Sustainable Energy Reviews. [e-journal] 8 (4), pp. 365381. http://dx.doi.org/10.1016/j.rser.2003.12.007

Pye, S., Anandarajah, G., Fais, B., McGlade, C. and Strachan, N. 2015. Pathways to deep decarbonization in the United Kingdom. [online] SDSN - IDDRI. Available at: http://deepdecarbonization.org/wp-content/uploads/2015/09/DDPP_GBR.pdf [Accessed on 05 March 2018]. 
Radaelli, C. M., 2010a. Rationality, power, management and symbols: four images of regulatory impact assessment. Scandinavian Political Studies. [e-journal] 33(2), pp. 164-188.

http://dx.doi.org/10.1111/j.1467-9477.2009.00245.x

Radaelli, C. M., 2010b. Regulating Rule-Making via Impact Assessment. Governance. [e-journal] 23 (1), pp. 89-108. http://dx.doi.org/10.1111/j.1468-0491.2009.01468.x

Rao, N. D., 2013. Distributional impacts of climate change mitigation in Indian electricity: The influence of governance. Energy Policy, [e-journal] 61, pp. 1344-1356.

http://dx.doi.org/10.1016/j.enpol.2013.05.103

Rausch, S., Metcalf, G.E. and Reilly, J.M., 2011. Distributional impacts of carbon pricing: A general equilibrium approach with micro-data for households. Energy Economics, [e-journal] 33, pp. S20S33. http://dx.doi.org/10.1016/j.eneco.2011.07.023

Renda, A., 2006. Impact Assessment in the EU: The State of the Art and the Art of the State. [online]. Brussels: Centre for European Policy Studies. Available at: http://aei.pitt.edu/32591/1/30._Impact_Assessment_in_the_EU.pdf [Accessed 01 March 2018].

Robinson, L.A., Hammitt, J.K. and Zeckhauser, R., 2014. The Role of Distribution in Regulatory Analysis and Decision Making. Regulatory Policy Program Working Paper RPR-2014-03. [online] Available from:

https://web.archive.org/web/20170705164747/https://www.hks.harvard.edu/content/download/70616/ 1255274/version/1/file/RPP_2014_03.pdf [Accessed 01 March 2018].

RPC, 2014. Regulatory Policy Committee: recommendations used when scrutinising impact assessments. [online] Available at: https://www.gov.uk/government/publications/how-the-regulatorypolicy-committee-scrutinises-impact-assessments/regulatory-policy-committee-recommendationsused-when-scrutinising-impact-assessments [Accessed 05 July 2018]. 
Russel, D. and Turnpenny, J., 2009. The politics of sustainable development in UK government: what role for integrated policy appraisal, Environment and Planning C: Government and Policy, [e-journal] 27, pp. 340-354. http://dx.doi.org/10.1068/c0810j

Schlör, H., Fischer, W. and Hake, J-H. 2013. Sustainable development justice and the Atkinson index: Measuring the distributional effects of the German energy transition. Applied Energy. [e-journal] 112, pp. 1493-1499. http://dx.doi.org/10.1016/j.apenergy.2013.04.020

Tiezzi, S., 2005. The welfare effects and the distributive impacts of carbon taxation on Italian households. Energy Policy, [e-journal] 33(12), pp.1597-1612. http://dx.doi.org/10.1016/j.enpol.2004.01.016

Turner, R. K. (2007) Limits to CBA in UK and European environmental policy: retrospects and future prospects. Environmental and Resource Economics. [e-journal] 37 (1), pp. 253-269. http://dx.doi.org/10.1007/s10640-007-9119-2

Turnpenny, J., Nilsson, M., Russel, D., Jordan, A., Hertin, J. and Nykvist, B., 2008. Why is integrating policy assessment so hard? A comparative analysis of the institutional capacities and constraints. Journal of Environmental Planning and Management. [e-journal] 51 (6), 759-775. http://dx.doi.org/10.1080/09640560802423541

Turnpenny, J., Radaelli, C.M., Jordan, A. and Jacob, K., 2009. The Policy and Politics of Policy Appraisal: Emerging Trends and New Directions. Journal of European Public Policy. [e-journal] 16(4), pp.640-653. http://dx.doi.org/10.1080/13501760902872783

Turnpenny, J., Russel, D. and Jordan, A., 2014. The challenge of embedding an ecosystems services approach: patterns of knowledge utilisation in public policy appraisal. Environment and Planning $C$ : Politics and Space. [e-journal] 32 (2), pp. 247-262. https://doi.org/10.1068/c1317j

Walker, G. 2007. Environmental justice and the distributional deficit in policy appraisal in the UK. Environmental Research Letters, [e-journal] 4(2), pp. http://dx.doi.org/10.1088/1748- 
Walker, G. 2010. Environmental justice, impact assessment and the politics of knowledge: The implications of assessing the social distribution of environmental outcomes. Environmental Impact Assessment Review [e-journal] 39(5), pp. 312-318. http://dx.doi.org/10.1016/j.eiar.2010.04.005

Watson, J. P., Wolff, J.M., Kuehnemund, M., Ward, B., Burke, S. and Kitchener, M., 2007. Evaluation of the commission's impact assessment system. Final Report. [online] UK: The Evaluation Partnership Limited (TEP). Available at: http://ec.europa.eu/smartregulation/impact/key_docs/docs/tep_eias_final_report.pdf [Accessed 01 March 2018].

White, V., 2014. Beyond average consumption: Development of a framework for assessing impact of policy proposals on different consumer groups: Updated report to Ofgem. [online] UK: Centre for Sustainable Energy. Available at: https://www.cse.org.uk/downloads/reports-andpublications/policy/beyond_average_consumption_update_2014.pdf [Accessed on 05 March 2018]. 


\section{Appendices}

Appendix 1: Scorecard Framework

\begin{tabular}{|c|c|c|c|c|c|}
\hline $\begin{array}{l}\text { 1. What type of } \\
\text { legislation does } \\
\text { the IA cover? }\end{array}$ & Primary & Secondary & Amendment & $\begin{array}{c}\text { EU } \\
\text { Legislation }\end{array}$ & \\
\hline $\begin{array}{l}\text { 2. What was the } \\
\text { designated area } \\
\text { of the policy? }\end{array}$ & $\begin{array}{c}\text { Open } \\
\text { Question }\end{array}$ & & & & \\
\hline $\begin{array}{l}\text { Consideration } \\
\text { of options }\end{array}$ & & & & & \\
\hline $\begin{array}{l}\text { 3. Was there a } \\
\text { 'do-nothing' } \\
\text { option? }\end{array}$ & $\begin{array}{c}\text { Yes } \\
1\end{array}$ & $\begin{array}{l}\text { No } \\
0\end{array}$ & & & $\begin{array}{c}\text { N/A } \\
-\end{array}$ \\
\hline $\begin{array}{l}\text { 4. Were there } \\
\text { more than one } \\
\text { option presented } \\
\text { (excluding 'do } \\
\text { nothing'?) }\end{array}$ & $\begin{array}{l}\text { Yes, with } \\
\text { a range of } \\
\text { feasible } \\
\text { options }\end{array}$ & $\begin{array}{c}\text { Yes, but } \\
\text { only with } \\
\text { varying } \\
\text { parameters } \\
\text { of the same } \\
\text { option } \\
1\end{array}$ & $\begin{array}{c}\text { Yes, but only one } \\
\text { feasible option } \\
1\end{array}$ & No & N/A \\
\hline $\begin{array}{l}\text { Cost and } \\
\text { Benefits }\end{array}$ & & & & & \\
\hline $\begin{array}{l}\text { 5. Were costs } \\
\text { quantified? }\end{array}$ & $\begin{array}{c}\text { Yes } \\
1\end{array}$ & $\begin{array}{c}\text { No } \\
0\end{array}$ & & & $\begin{array}{c}\text { N/A } \\
-\end{array}$ \\
\hline $\begin{array}{l}\text { 6. Were benefits } \\
\text { quantified? }\end{array}$ & $\begin{array}{c}\text { Yes } \\
1\end{array}$ & $\begin{array}{c}\text { No } \\
0\end{array}$ & & & $\begin{array}{c}\text { N/A } \\
-\end{array}$ \\
\hline
\end{tabular}




\begin{tabular}{|c|c|c|c|c|}
\hline $\begin{array}{l}\text { 7. Were costs } \\
\text { qualitatively } \\
\text { discussed? }\end{array}$ & $\begin{array}{c}\text { Yes } \\
1\end{array}$ & $\begin{array}{c}\text { No } \\
0\end{array}$ & & $\begin{array}{c}\text { N/A } \\
-\end{array}$ \\
\hline $\begin{array}{l}\text { 8. Were benefits } \\
\text { qualitatively } \\
\text { discussed? }\end{array}$ & $\begin{array}{c}\text { Yes } \\
1\end{array}$ & $\begin{array}{c}\text { No } \\
0\end{array}$ & & $\begin{array}{c}\text { N/A } \\
-\end{array}$ \\
\hline Impact tests & & & & \\
\hline $\begin{array}{l}\text { 10. Were any } \\
\text { economic } \\
\text { impacts (e.g. } \\
\text { impacts on bills, } \\
\text { businesses, } \\
\text { labour market) } \\
\text { discussed? }\end{array}$ & $\begin{array}{c}\text { Yes } \\
1\end{array}$ & $\begin{array}{c}\text { No } \\
0 \\
0\end{array}$ & & $\begin{array}{c}\text { N/A } \\
-\end{array}$ \\
\hline $\begin{array}{l}\text { 11. Were any } \\
\text { environmental } \\
\text { impacts (e.g. air } \\
\text { quality, } \\
\text { emissions) } \\
\text { discussed? }\end{array}$ & $\begin{array}{c}\text { Yes } \\
1\end{array}$ & $\begin{array}{c}\text { No } \\
0\end{array}$ & & $\begin{array}{c}\text { N/A } \\
-\end{array}$ \\
\hline $\begin{array}{l}\text { 12. Has } \\
\text { Distributional } \\
\text { Analysis been } \\
\text { undertaken? }\end{array}$ & Yes & $\begin{array}{l}\text { Yes, } \\
\text { implicitly } \\
\text { through } \\
\text { proxies }^{1} \\
1\end{array}$ & $\begin{array}{l}\text { No } \\
\\
0\end{array}$ & $\begin{array}{c}\text { N/A } \\
-\end{array}$ \\
\hline
\end{tabular}




\begin{tabular}{|c|c|c|c|c|c|}
\hline $\begin{array}{l}\text { 13. Were any } \\
\text { social impacts } \\
\text { with } \\
\text { distributional } \\
\text { dimensions }{ }^{2} \\
\text { discussed? }\end{array}$ & $\begin{array}{l}\text { Yes, all of } \\
\text { them }\end{array}$ & $\begin{array}{l}\text { Yes, some } \\
\text { of them }\end{array}$ & No & & $\begin{array}{c}\text { N/A } \\
-\end{array}$ \\
\hline $\begin{array}{l}\text { 14. Is absence of } \\
\text { DI consideration } \\
\text { justified? }\end{array}$ & $\begin{array}{c}\text { Yes } \\
1\end{array}$ & $\begin{array}{c}\text { No } \\
0\end{array}$ & & & $\begin{array}{c}\text { N/A } \\
1\end{array}$ \\
\hline $\begin{array}{l}\text { Discussion } \\
\text { methods }\end{array}$ & & & & & \\
\hline $\begin{array}{l}\text { 15. Was there a } \\
\text { qualitative } \\
\text { discussion of } \\
\text { distributional } \\
\text { impacts? }\end{array}$ & $\begin{array}{c}\text { All } \\
\text { options }\end{array}$ & $\begin{array}{c}\text { Only } \\
\text { preferred } \\
\text { option }\end{array}$ & $\begin{array}{l}\text { Yes, but only in a } \\
\text { generic manner }\end{array}$ & None & N/A \\
\hline $\begin{array}{l}\text { 16. Were } \\
\text { distributional } \\
\text { impacts } \\
\text { quantified (fuel } \\
\text { poverty)? }\end{array}$ & $\begin{array}{l}\text { Yes, all } \\
\text { options }\end{array}$ & $\begin{array}{c}\text { Only } \\
\text { preferred } \\
\text { option }\end{array}$ & No & & N/A \\
\hline $\begin{array}{l}\text { 17. Were } \\
\text { distributional } \\
\text { impacts } \\
\text { monetised? }\end{array}$ & $\begin{array}{l}\text { Yes, all } \\
\text { options }\end{array}$ & $\begin{array}{c}\text { Only } \\
\text { preferred } \\
\text { option }\end{array}$ & No & & N/A \\
\hline
\end{tabular}




\begin{tabular}{|c|c|c|c|}
\hline $\begin{array}{l}\text { 18. Was Equity- } \\
\text { Weighting used } \\
\text { to include DI in } \\
\text { NPV } \\
\text { calculations? }\end{array}$ & $\begin{array}{c}\text { Yes } \\
1\end{array}$ & $\begin{array}{c}\text { No } \\
0\end{array}$ & $\begin{array}{c}\text { N/A } \\
-\end{array}$ \\
\hline $\begin{array}{l}\text { 19. Was the } \\
\text { Multi-Criteria } \\
\text { Method used if } \\
\text { DI's were not } \\
\text { quantifiable? }\end{array}$ & $\begin{array}{c}\text { Yes } \\
1\end{array}$ & $\begin{array}{c}\text { No } \\
0\end{array}$ & $\begin{array}{c}\text { N/A } \\
-\end{array}$ \\
\hline $\begin{array}{l}\text { 20. Is choice (or } \\
\text { absence) of } \\
\text { impact } \\
\text { evaluation } \\
\text { justified (e.g. } \\
\text { subject of } \\
\text { proportionality)? }\end{array}$ & $\begin{array}{c}\text { Yes } \\
1\end{array}$ & $\begin{array}{c}\text { No } \\
0\end{array}$ & $\begin{array}{c}\text { N/A } \\
1\end{array}$ \\
\hline Overall & & & \\
\hline $\begin{array}{l}21 . \text { Does the IA } \\
\text { include a plan to } \\
\text { mitigate } \\
\text { (negative) } \\
\text { /increase } \\
\text { (positive) } \\
\text { potential } \\
\text { distributional } \\
\text { impacts? }\end{array}$ & $\begin{array}{c}\text { Yes } \\
1\end{array}$ & No & $\begin{array}{c}\text { N/A } \\
-\end{array}$ \\
\hline
\end{tabular}




\begin{tabular}{|l|c|c|c|c|}
\hline $\begin{array}{l}\text { 22. Do DIs have } \\
\text { any discernible }\end{array}$ & Yes & No & & N/A \\
impact on final & 1 & 0 & & - \\
decision? & & & & \\
\hline
\end{tabular}

${ }^{1}$ Through discussion on fuel poverty

${ }^{2}$ rural proofing, equality measures: gender, marriage, health, ethnic group, age, location 
Appendix 2: Overview of Impact Assessments

Impact Assessments with Distributional Analysis

\begin{tabular}{|c|c|c|c|c|}
\hline IA & Year of Publishment & Policy area & Overall Score & Rating \\
\hline Impact Assessment of the & & Climate & & O \\
\hline Climate Change Act & 2009 & Change & 5 & \\
\hline Impact Assessment of UK & & Power & & 0 \\
\hline Renewable Energy Strategy & 2009 & Generation & 8 & \\
\hline \multicolumn{5}{|l|}{ Impact Assessment of Feed- } \\
\hline \multicolumn{5}{|l|}{ in Tariffs for Small-Scale, } \\
\hline Low Carbon, Electricity & & Power & & \\
\hline Generation & 2009 & Generation & 6 & \\
\hline \multicolumn{5}{|l|}{ Impact Assessment of } \\
\hline proposals for a UK & & & & O \\
\hline \multicolumn{5}{|l|}{ Renewable Energy Strategy } \\
\hline - Renewable Heat & 2009 & Buildings & 7 & \\
\hline \multicolumn{5}{|l|}{ Impact Assessment of EU } \\
\hline \multicolumn{5}{|l|}{ Climate and Energy } \\
\hline \multicolumn{5}{|l|}{ package, the revised EU } \\
\hline \multicolumn{5}{|l|}{ Emissions Trading System } \\
\hline \multicolumn{5}{|l|}{ Directive and meeting the } \\
\hline UK non-traded target & & Climate & & \\
\hline through UK carbon budgets. & 2009 & Change & 11 & \\
\hline \multicolumn{5}{|l|}{ Extending the Carbon } \\
\hline Emissions Reduction Target & & Climate & & 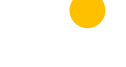 \\
\hline to December 2012 & 2010 & Change & 7 & \\
\hline
\end{tabular}




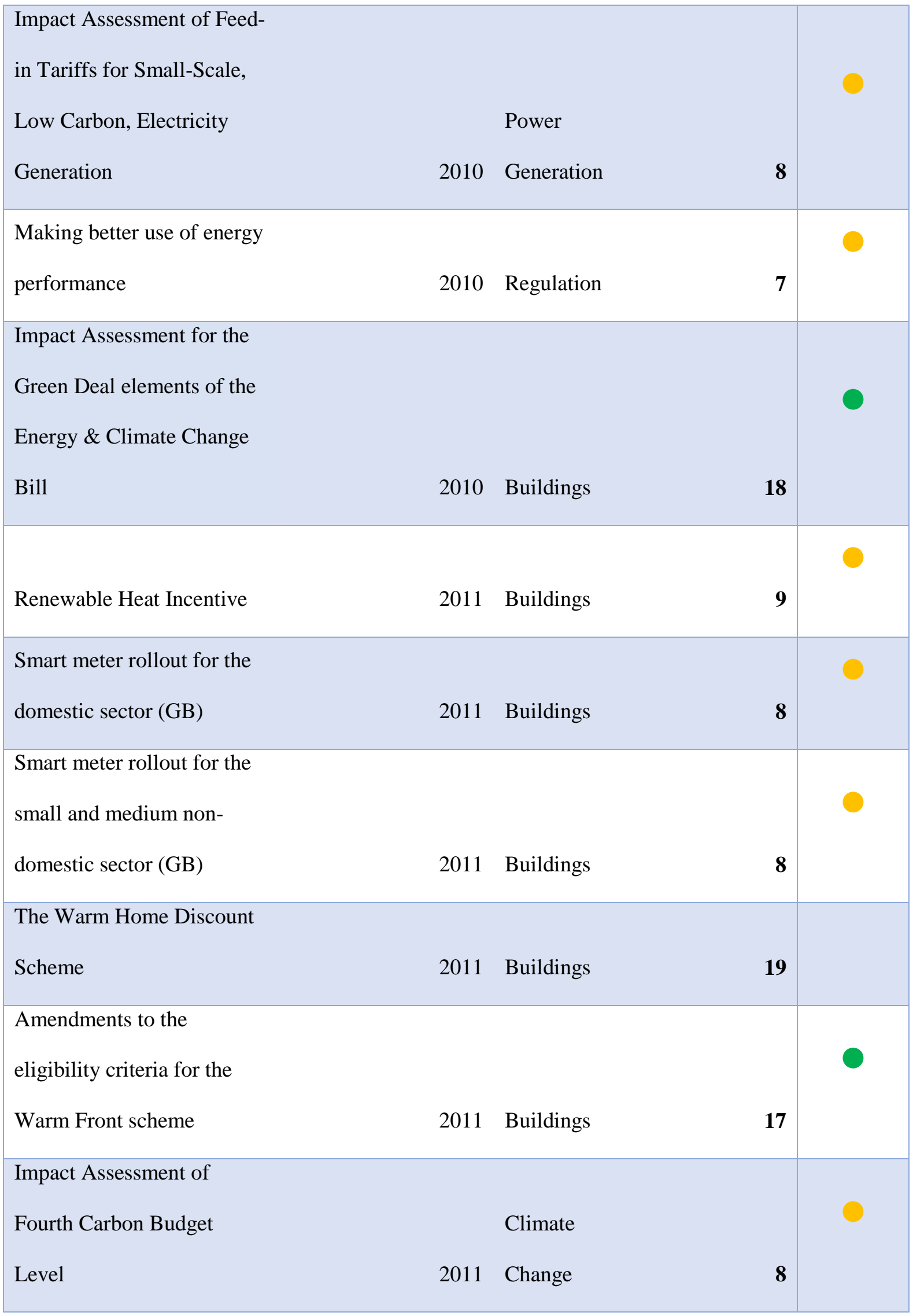




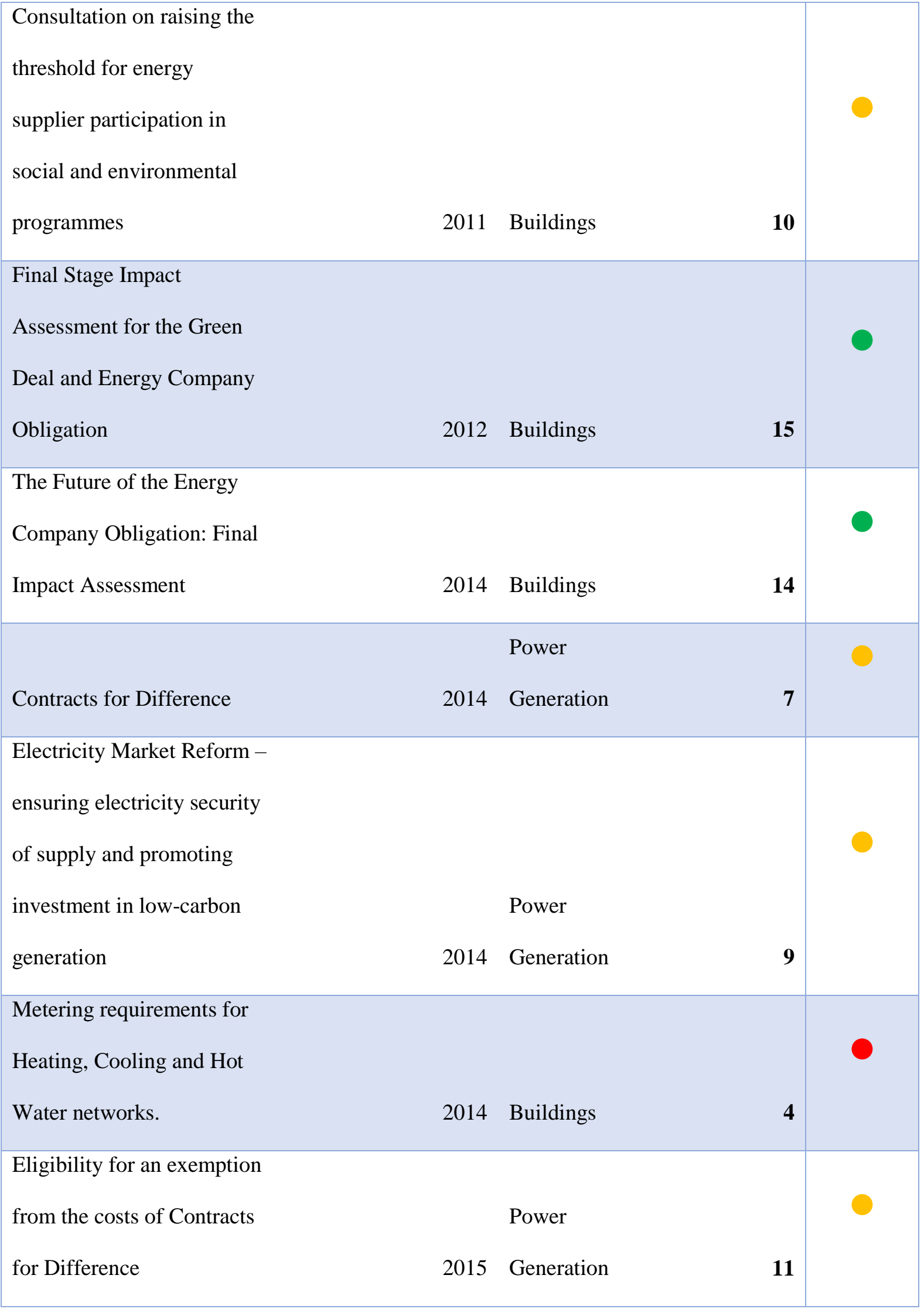




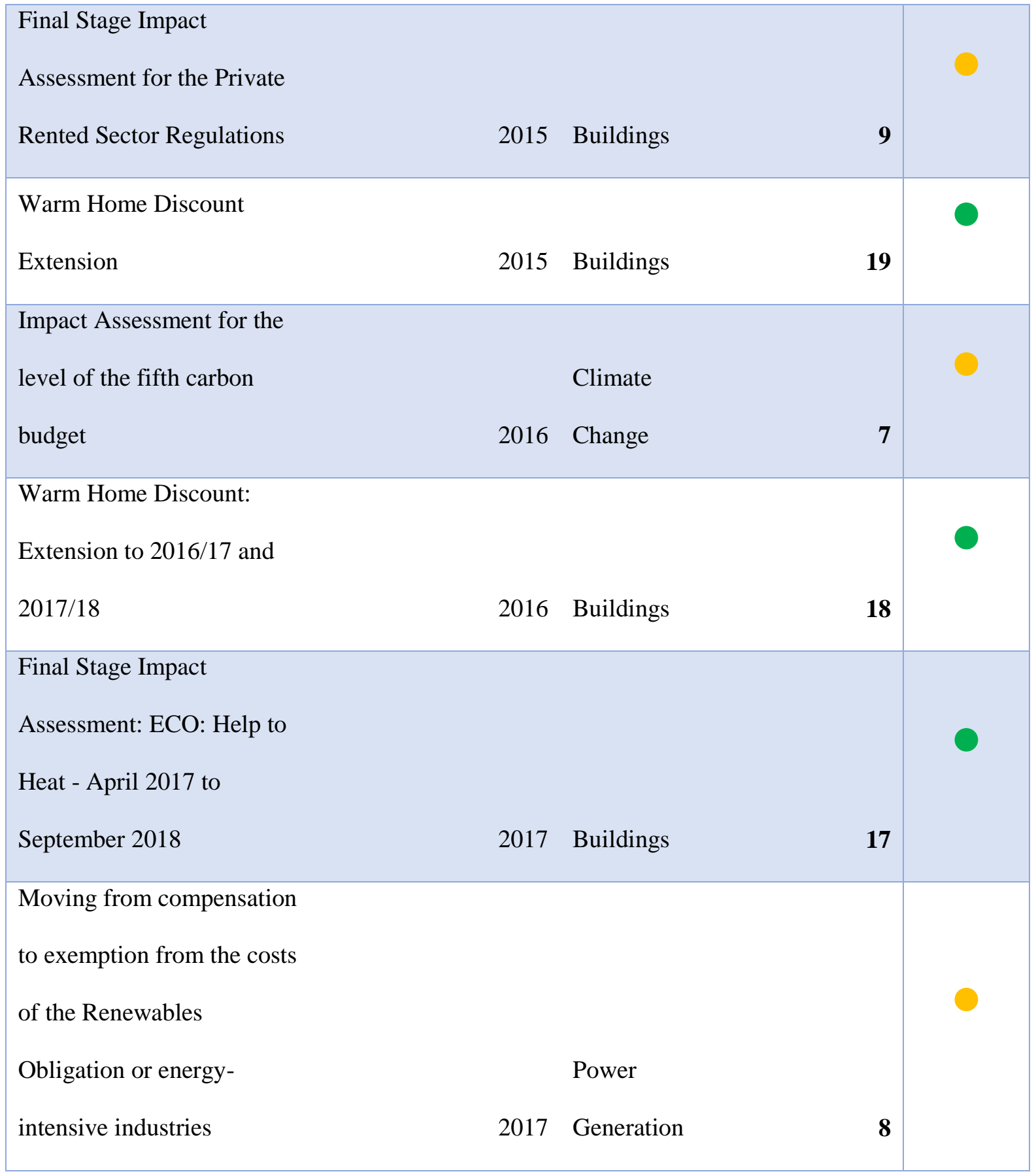




\begin{tabular}{|c|c|c|c|c|}
\hline IA & Year of publishment & Policy area & Overall Score & Rating \\
\hline $\begin{array}{l}\text { Impact Assessment of } \\
\text { proposals for a UK }\end{array}$ & & & & \\
\hline Renewable & & & & \\
\hline Energy Strategy - & & Power & & \\
\hline Renewable Electricity & 2009 & Generation & 2 & \\
\hline \multicolumn{5}{|l|}{ Impact Assessment of First } \\
\hline \multicolumn{5}{|l|}{ Stage Transposition of EU } \\
\hline \multicolumn{5}{|l|}{ Legislation to Include } \\
\hline \multicolumn{5}{|l|}{ Aviation in the European } \\
\hline \multicolumn{5}{|l|}{ Union Emissions Trading } \\
\hline System (EU ETS) & 2009 & Regulation & 2 & \\
\hline \multicolumn{5}{|l|}{ Impact Assessment for the } \\
\hline $\begin{array}{l}\text { Government Response to } \\
\text { the Consultation on the }\end{array}$ & & & & \\
\hline \multicolumn{5}{|l|}{ Grandfathering Policy of } \\
\hline \multicolumn{5}{|l|}{ Support for Dedicated } \\
\hline \multicolumn{5}{|l|}{ Biomass, Anaerobic } \\
\hline \multicolumn{5}{|l|}{ Digestion and Energy from } \\
\hline Waste Under the & & Power & & \\
\hline Renewables Obligation & 2010 & Generation & 3 & \\
\hline $\begin{array}{l}\text { Impact Assessment of } \\
\text { offshore carbon dioxide }\end{array}$ & & & & \\
\hline storage licensing regime & 2010 & $\mathrm{CCS}$ & 3 & \\
\hline
\end{tabular}




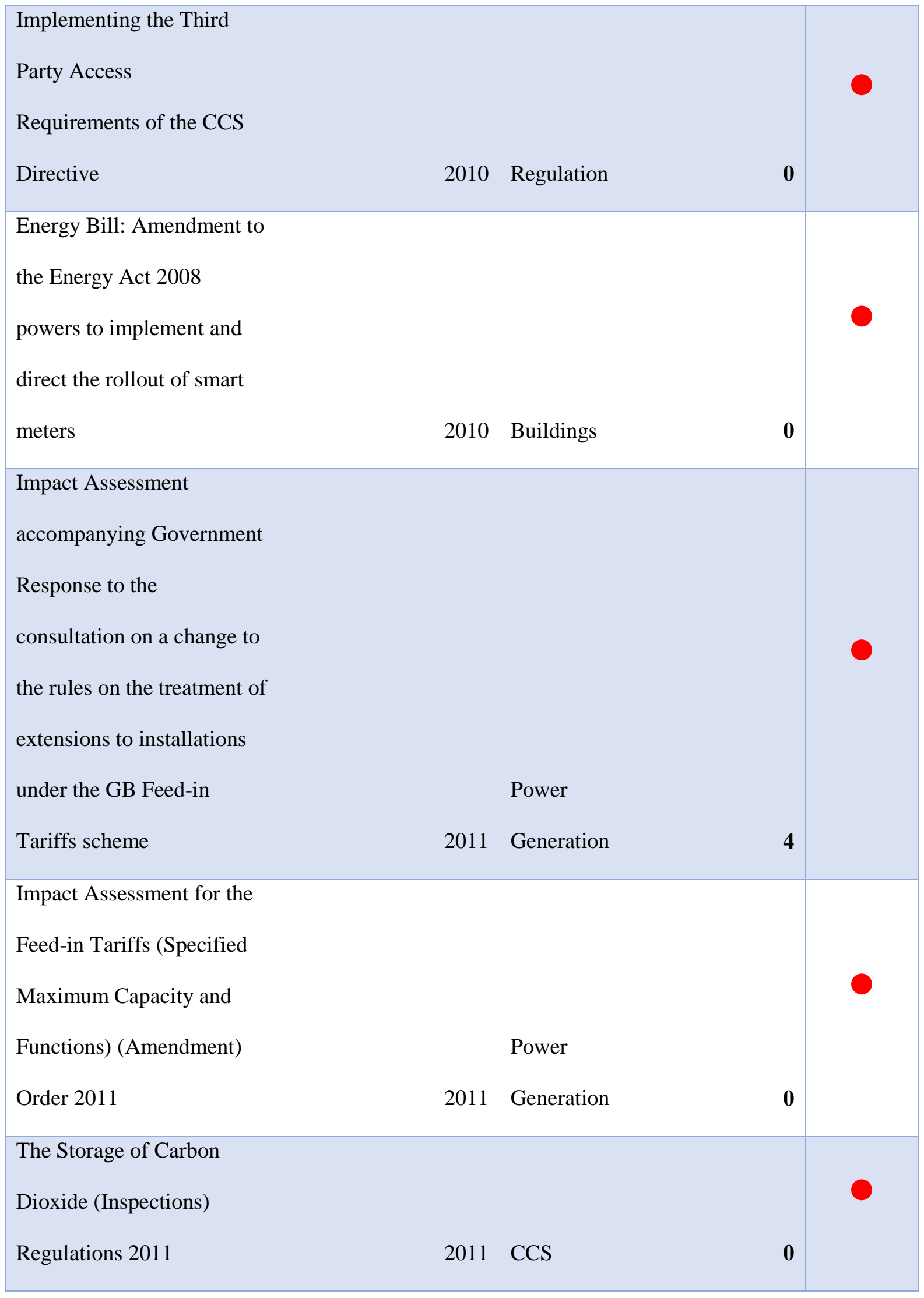




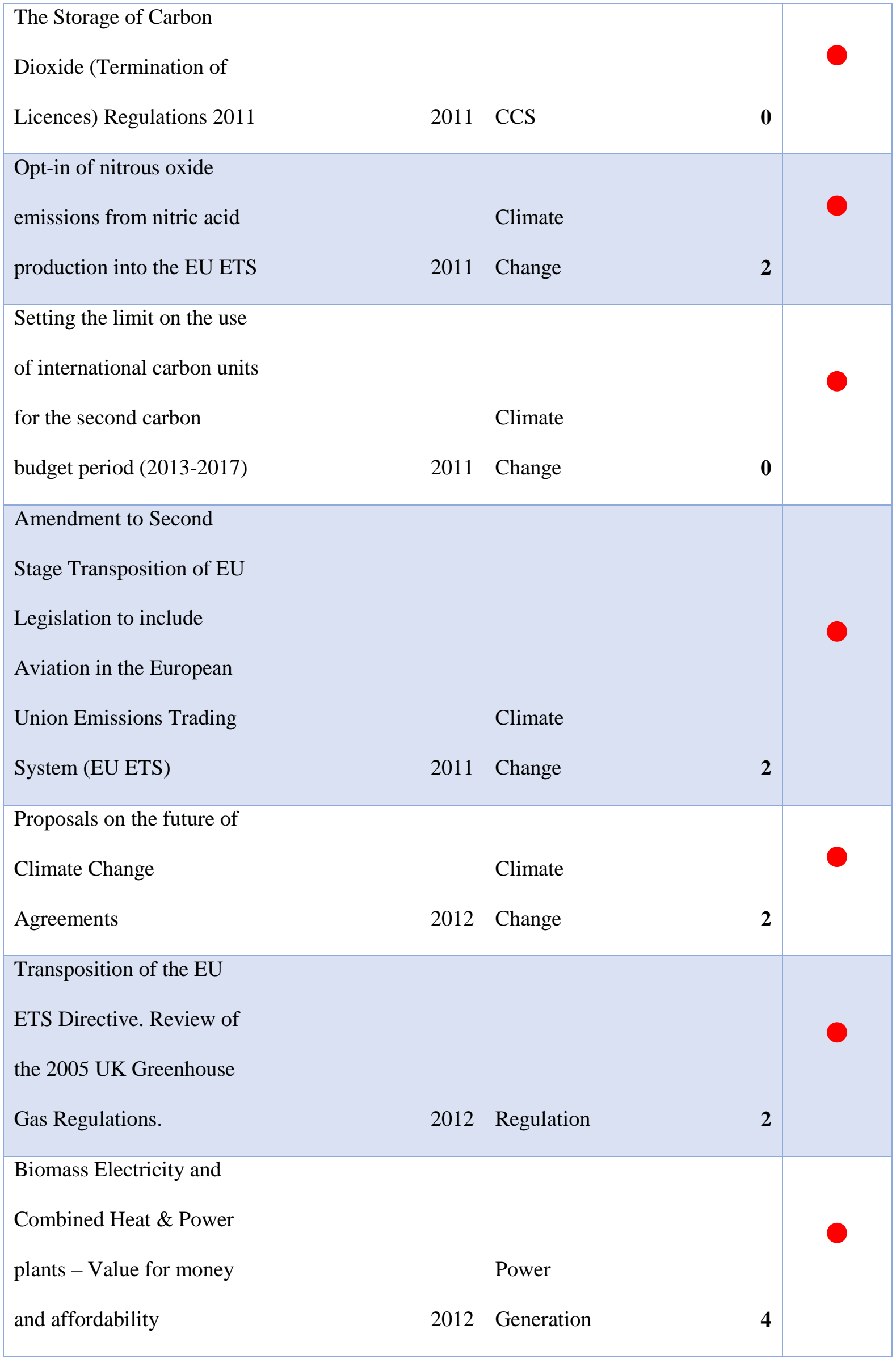




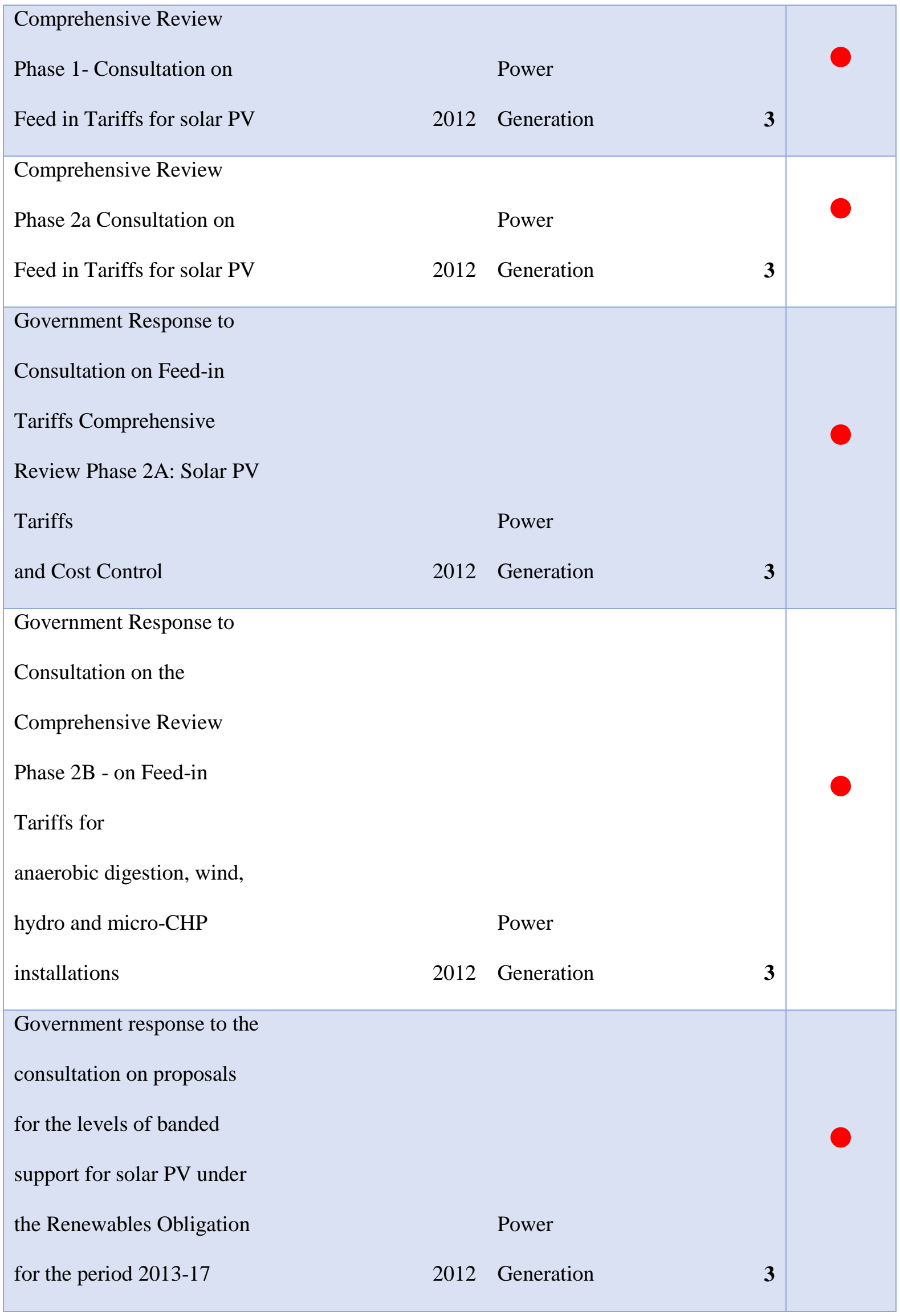




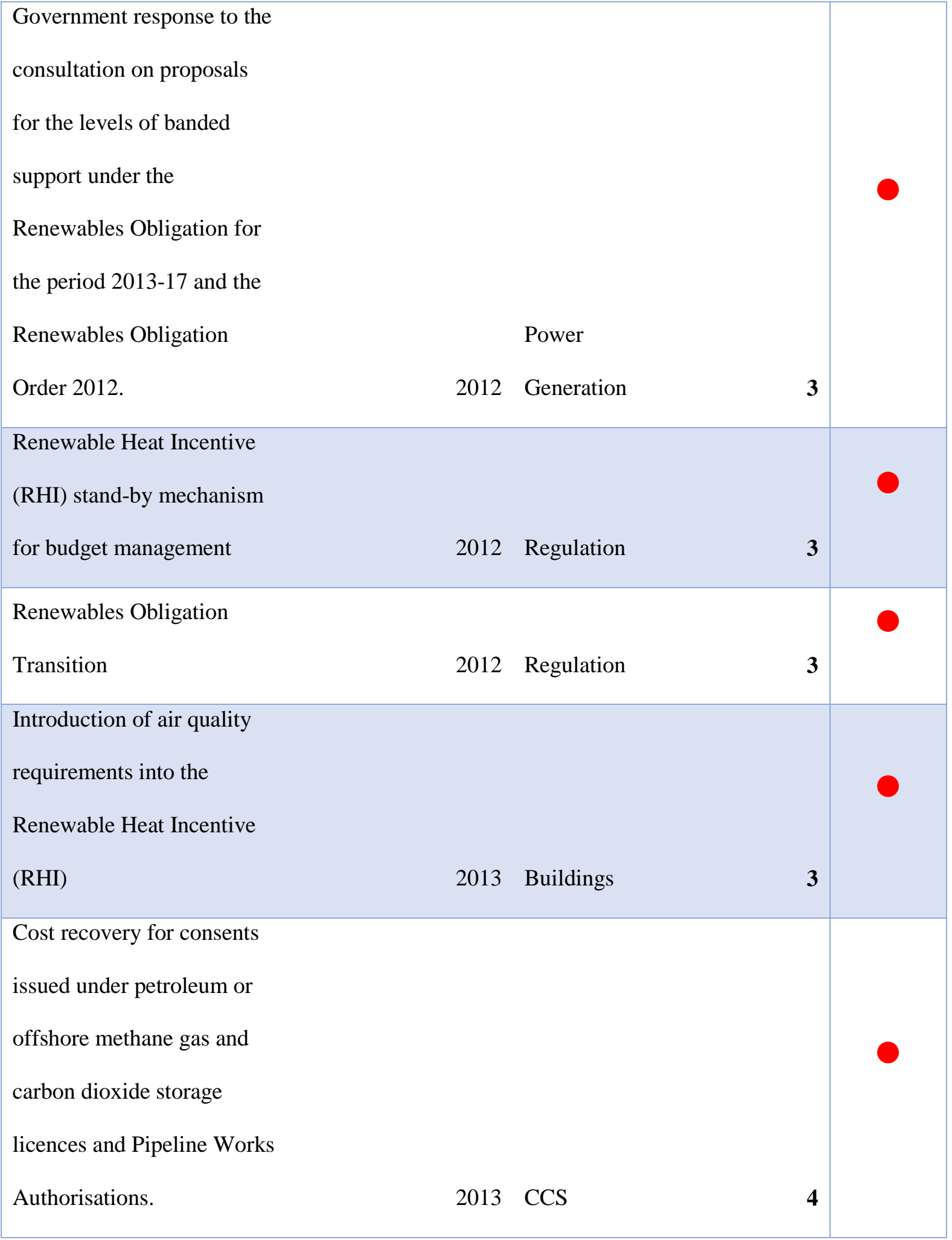




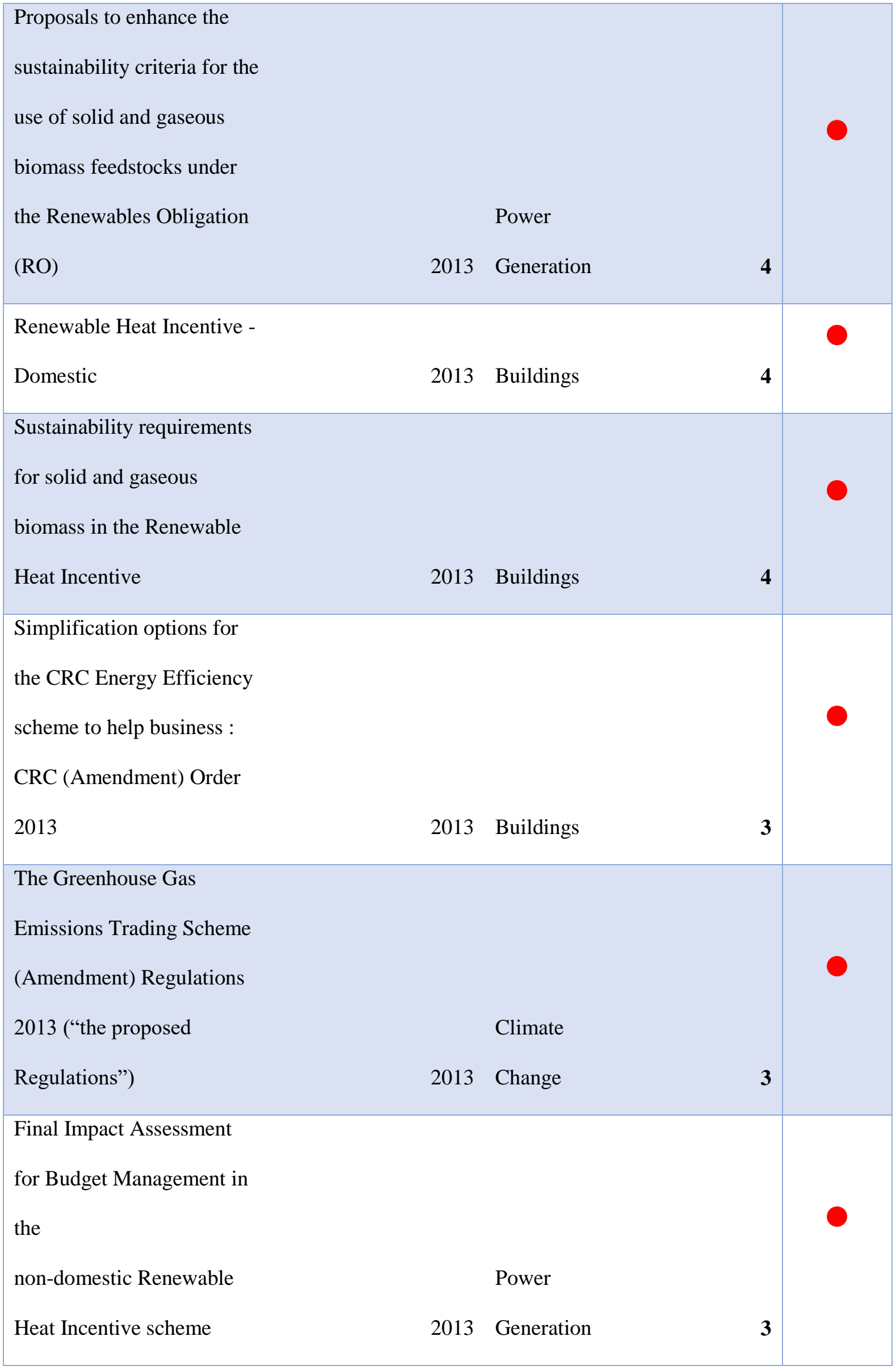




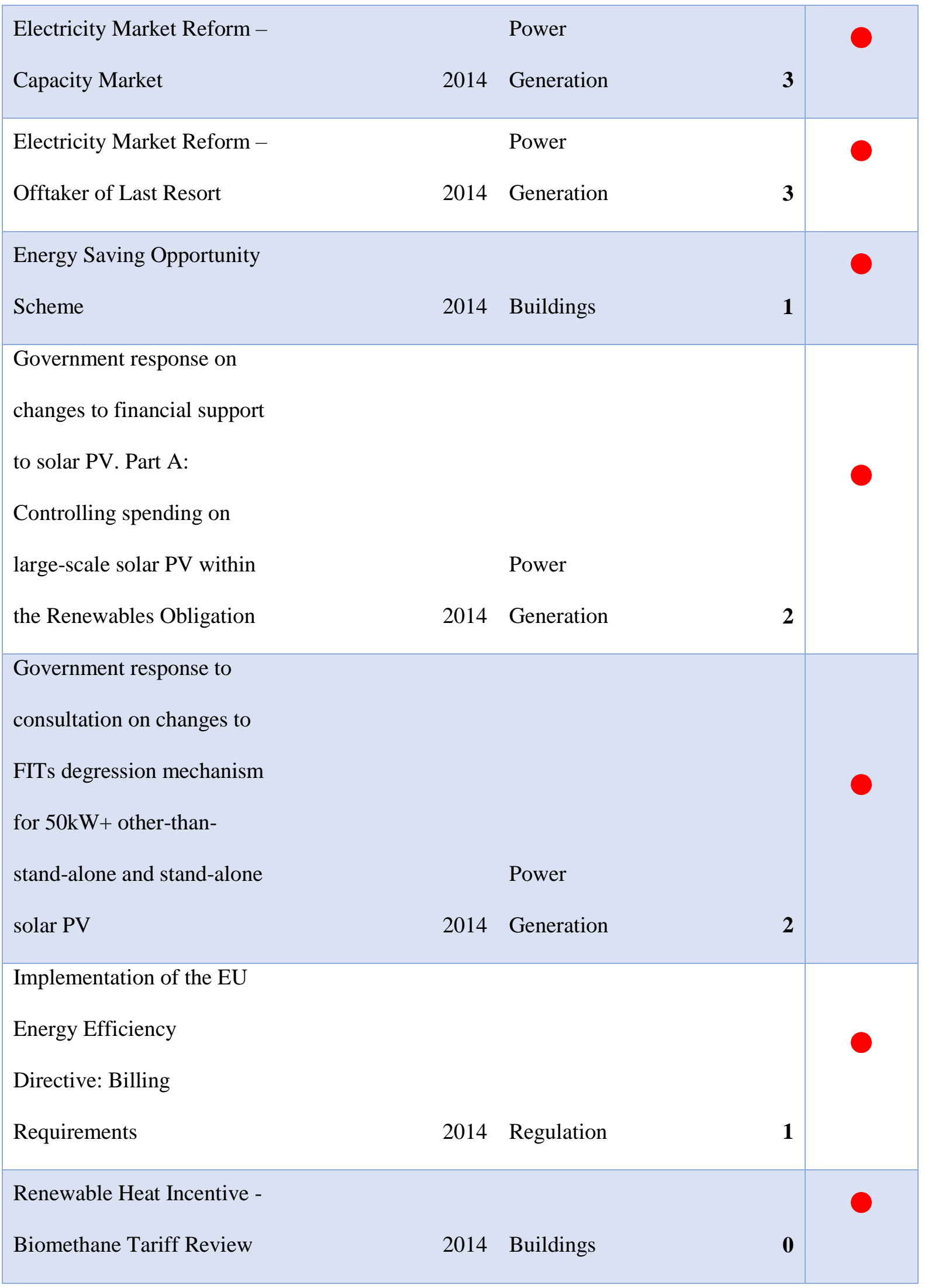




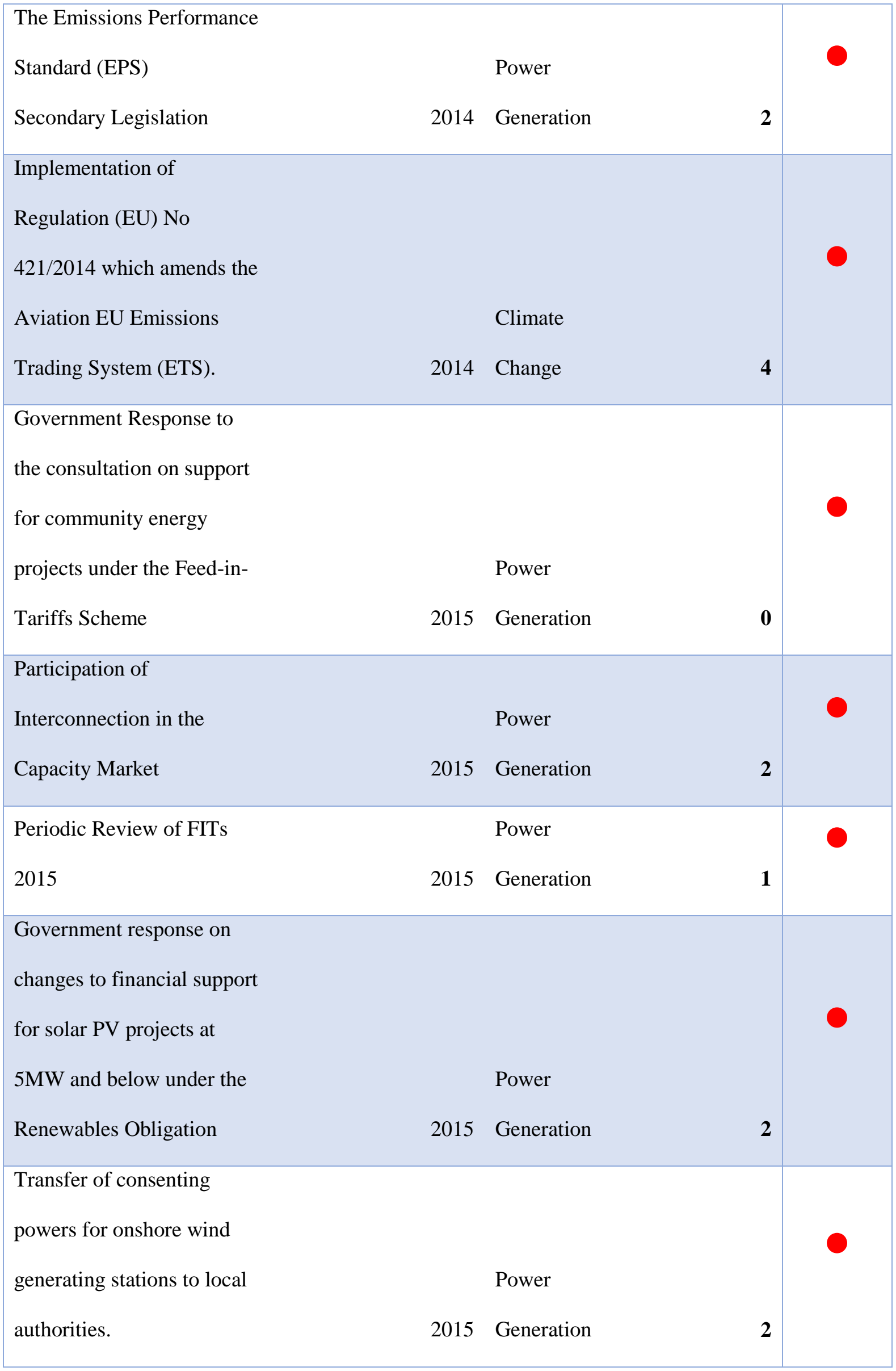




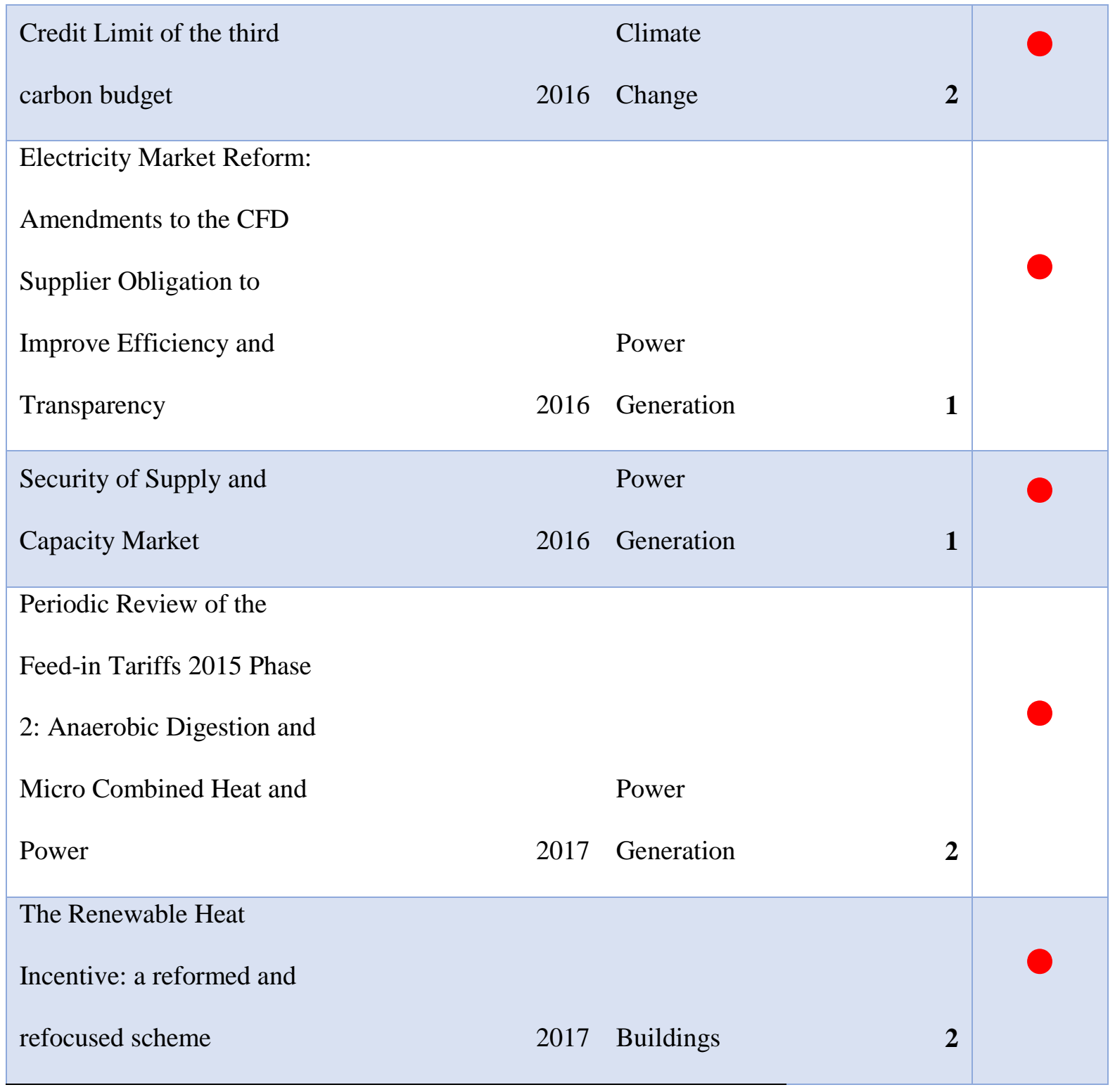

